Article

\title{
Carbon Nanotubes Hybrid Hydrogels for Environmental Remediation: Evaluation of Adsorption Efficiency under Electric Field
}

\author{
Giuseppe Cirillo $^{1, *(\mathbb{D})}$, Manuela Curcio ${ }^{1}{ }^{(\mathbb{D}}$, Lorenzo Francesco Madeo ${ }^{2}$, Francesca Iemma ${ }^{1}$, Giovanni De Filpo ${ }^{3} \mathbb{D}$, \\ Silke Hampel ${ }^{2}$ (D) and Fiore Pasquale Nicoletta ${ }^{1}$ (D)
}

1 Department of Pharmacy, Health and Nutritional Sciences, University of Calabria, 87036 Rende, Italy; manuela.curcio@unical.it (M.C.); francesca.iemma@unical.it (F.I.); fiore.nicoletta@unical.it (F.P.N.)

2 Leibniz Institute of Solid State and Material Research Dresden, 01069 Dresden, Germany; l.f.madeo@ifw-dresden.de (L.F.M.); s.hampel@ifw-dresden.de (S.H.)

3 Department of Chemistry and Chemical Technologies, University of Calabria, 87036 Rende, Italy; giovanni.defilpo@unical.it

* Correspondence: giuseppe.cirillo@unical.it; Tel.: +39-0984493208

check for

updates

Citation: Cirillo, G.; Curcio, M.; Madeo, L.F.; Iemma, F.; De Filpo, G.; Hampel, S.; Nicoletta, F.P. Carbon Nanotubes Hybrid Hydrogels for Environmental Remediation: Evaluation of Adsorption Efficiency under Electric Field. Molecules 2021, 26,7001. https://doi.org/10.3390/ molecules 26227001

Academic Editor: Jacques Lalevee

Received: 1 October 2021

Accepted: 18 November 2021

Published: 19 November 2021

Publisher's Note: MDPI stays neutral with regard to jurisdictional claims in published maps and institutional affiliations.

Copyright: (c) 2021 by the authors. Licensee MDPI, Basel, Switzerland. This article is an open access article distributed under the terms and conditions of the Creative Commons Attribution (CC BY) license (https:// creativecommons.org/licenses/by/ $4.0 /)$.

\begin{abstract}
The performance of Carbon Nanotubes hybrid hydrogels for environmental remediation was investigated using Methylene Blue (MB), Rhodamine B (RD), and Bengal Rose (BR) as model contaminating dyes. An acrylate hydrogel network with incorporated CNT was synthesized by photo-polymerization without any preliminary derivatization of CNT surface. Thermodynamics, isothermal and kinetic studies showed favorable sorption processes with the application of an external $12 \mathrm{~V}$ electric field found to be able to influence the amount of adsorbed dyes: stronger interactions with cationic MB molecules ( $q_{\exp }$ and $q_{\text {exp }}^{12}$ of 19.72 and $33.45 \mathrm{mg} \mathrm{g}^{-1}$, respectively) and reduced affinity for anionic RD ( $q_{\exp }$ and $q_{\text {exp }}^{12}$ of 28.93 and $13.06 \mathrm{mg} \mathrm{g}^{-1}$, respectively) and neutral BR ( $q_{\exp }$ and $q_{\exp }^{12}$ of 36.75 and $15.85 \mathrm{mg} \mathrm{g}^{-1}$, respectively) molecules were recorded. The influence of $\mathrm{pH}$ variation on dyes adsorption was finally highlighted by reusability studies, with the negligible variation of adsorption capacity after five repeated sorption cycles claiming for the suitability of the proposed systems as effective sorbent for wastewater treatment.
\end{abstract}

Keywords: wastewater treatment; hybrid hydrogel; carbon nanotubes; isothermal studies; kinetic studies

\section{Introduction}

The environmental contamination is becoming the major concern of government regulatory agencies, due to the harmful effects on ecosystems [1,2], with organic dyes used in textile, plastic, wood, paper, and food industries representing the most challenging contaminants for an effective environmental remediation [3,4]. Their chemical structure, often consisting in water soluble aromatic amines, together with the negligible biodegradation profiles, is responsible for severe adverse effects on human health, with kidney, liver, central nervous system, and cancer diseases being the most dangerous disorders [5-7].

As a consequence of the increasing demand for effective remediation methods, several different technologies (e.g., ion exchange, electro- and light- degradation, bioremediation, biosorption, and membrane separation) have been established and are continuously upgraded for the removal of toxic components from wastewater [8-10].

Biosorption, involving the use of polysaccharide and protein materials from animal or vegetable origin appropriately formulated into different structures [11,12], is a widely explored technology for the removal of organic dyes since it couples the cost-effectiveness and high efficiency of sorption methods with the biocompatibility and sustainability of natural polymers allowing for a reduction environmental impact [13-15]. Hydrogels based on natural polymers are emerging as highly effective absorbers due to their ability to store 
a large amount of water and the possibility to introduce tailored chemical functionalities for the selective interaction with organic contaminants $[16,17]$. On the other hand, such materials suffer from some severe drawbacks limiting their applicability in industrial practice, mainly related to their poor mechanical properties $[18,19]$. To overcome these limitations, several attempts have been made for the development of hybrid materials with improved performance consisting in natural polymers crosslinked/inserted into acrylate networks [20,21]. Moreover, great attention has been focused on the development of composite materials where inorganic components such as silica, clay, metal, or carbon nanostructures are incorporated within a polymer network, with the ultimate aim to enhance the adsorption capacity due to the large specific surface area of nanoparticle systems [22,23]. Among others, carbon nanostructures, and carbon nanotubes (CNT) in particular, offer key advantages in the preparation of highly effective sorbent materials because of their hollow and layered surface allowing for high interaction with organic molecules via $\pi-\pi$ staking [24-26]. On the other hand, the applicability of unmodified CNT in adsorption processes is significantly restricted by the absence of polar functional groups resulting in a poor interaction with hydrophilic compounds [27]. Thus, it is evident the importance of both CNT and polymer counterparts for an effective wastewater remediation, with the modification of CNT surface allowing the enhancement of the eco- and biocompatibility of the composite sorbents [28,29].

We previously proved the possibility to insert CNT into composite hydrogels by a modified "grafting from" approach consisting in the radical polymerization of acrylamide (AAm), N-N'-ethylenebisacrylamide (EBA) in the presence of Gelatin-coated multi-walled CNT (MWCNT) [30]. The resulting system was evaluated in terms of affinity for charged drugs, and proposed as an electro-responsive delivery device, with the release profiles closely found to be dependent on both the net charge of the drug molecule and the applied external voltage.

The application of an electric field to improve the performance of sorbent materials was extensively explored in the literature, e.g., for the adsorption of asphaltenes at a pendent drop interface [31], or for the adsorption of different types of proteins onto optically transparent carbon electrodes [32]. It was found that the electric-field induced fluid flows help asphaltene molecules to interact with the water-oil interface, and that the adsorption of hard proteins was more susceptible to the application of the external electric field compared to soft proteins, due to the different electric behavior of the two classes of macromolecules.

Within the present study, we aim to test the versatility of such hybrid hydrogels, investigating their ability to adsorb three different organic dyes with different electric behavior such as Methylene Blue (MB), Rhodamine B (RD), and Bengal Rose (BR). For a more exhaustive characterization, the mechanism of dyes adsorption, kinetics, and thermodynamics parameters were determined by suitable empirical models.

\section{Results and Discussion}

\subsection{Synthesis and Characterization of Hybrid Hydrogels}

Different methodologies were proposed for the fabrication of hybrid hydrogels $\left(\mathrm{HG}_{\mathrm{NT}}\right)$ based on the incorporation of MWCNT into the polymer networks [33-35]. Here, we used a previously reported strategy based on a modified "grafting from" approach involving the co-polymerization of Gelatin (Gel) coated MWCNT (Gel@MWCNT) in the presence of AAm and EBA as plasticizing and crosslinking monomers, respectively.

In detail, individual MWNT of about 20-30 graphene walls (10-30 $\mu \mathrm{m}$ length, $10-80 \mathrm{~nm}$ outer diameter, 5-25 nm inner diameter) were firstly synthesized by an aerosol assisted chemical vapor deposition method where cyclohexane and ferrocene acted as a carbon source and metal-organic catalyst precursor, respectively [36]. Then, MWCNT underwent non-covalent functionalization with Gel to improve their stability in water. The strong hydrophobic behavior of pristine materials resulted, indeed, in the formation of big aggregates in water media of $1.70 \mu \mathrm{m}$ average hydrodynamic diameter (polydispersity index 
PDI of 0.30). On the other hand, Gel@MWCNT showed a reduced tendency to agglomerate (0.34 $\mu \mathrm{m}$ hydrodynamic diameter, PDI of 0.05) and were thus used for the synthesis of hybrid hydrogels. Gel@MWCNT were inserted in the pre-polymerization feed together with the selected amount of acrylate monomers and photo-polymerized to obtain the hybrid hydrogels $\mathrm{HG}_{\mathrm{NT}}$, while control samples $\left(\mathrm{HG}_{\mathrm{B}}\right)$ were prepared when reaction was conducted using Gel instead of Gel@MWCNT.

As extensively investigated in the literature, the employed synthetic procedure is based on the ability of growing polymer radicals to be linked on the defective site of MWCNT surface, resulting in chain termination and MWCNT immobilization into the polymer network [30]. Moreover, this approach is effective for the incorporation of MWCNT into the hydrogel structure, as confirmed by Scanning Electron Microscopy (SEM), FT-IR, Raman, and Differential Scanning Calorimetry (DSC).

The evaluation of the hydrogel morphology (Figure 1a,b) showed MWCNT well embedded into the $\mathrm{HG}_{\mathrm{NT}}$ polymer matrix (Figure $1 \mathrm{~b}$ ).

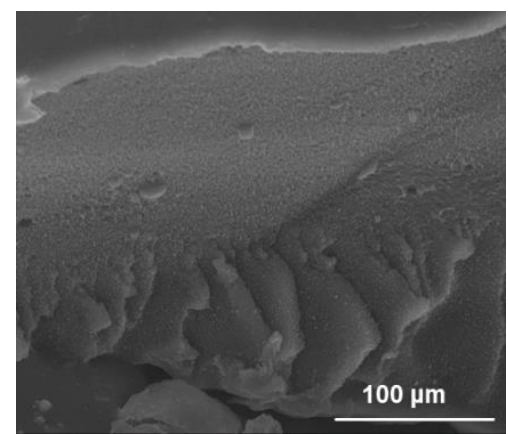

(a)

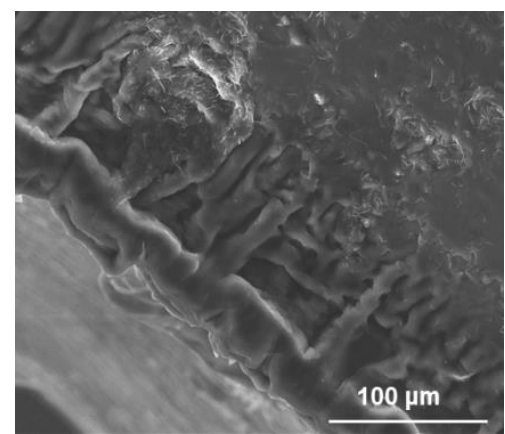

(b)

Figure 1. SEM images of (a) $\mathrm{HG}_{\mathrm{B}}$ and (b) $\mathrm{HG}_{\mathrm{NT}}$ samples, showing the presence of MWCNT homogeneously embedded in the polymer network of $\mathrm{HG}_{\mathrm{NT}}$.

FT-IR (Supplementary Materials Figure S1) and Raman analysis [30] were used to assess the covalent incorporation of MWCNT inside the polymer network. In detail, the FTIR spectrum of $\mathrm{HG}_{\mathrm{NT}}$ (Figure S1 in Supplementary Materials) showed the typical CNT band at $1615 \mathrm{~cm}^{-1}(\mathrm{C}=\mathrm{C}$ stretching $)$ [37] in the $\mathrm{HG}_{\mathrm{NT}}$ spectrum, while the modification in the intensity of $\mathrm{D}$ and $\mathrm{G}$ bands $\left(\mathrm{I}_{\mathrm{D}} / \mathrm{I}_{\mathrm{G}}\right.$ ratio) in Raman spectra of pristine and polymerized MWCNT [30] clearly showed the covalent attachment of polymer chains onto the MWCNT surface. It is well known, indeed, that the $D\left(1304 \mathrm{~cm}^{-1}\right)$ and $G\left(1589 \mathrm{~cm}^{-1}\right)$ bands are related to the disorder and graphitic characters of MWCNT, respectively. The presence of defects sites on pristine MWCNT surface induced by the purification procedure resulted in an $\mathrm{I}_{\mathrm{D}} / \mathrm{I}_{\mathrm{G}}$ ratio of around 1.20 [38], becoming 1.80 in the case of $\mathrm{HG}_{\mathrm{NT}}$, as a confirmation of the increased disorder due to the covalent bonds formation.

Moreover, the covalent incorporation of MWCNT significantly modified the thermal and electrical properties of $\mathrm{HG}_{\mathrm{B}}$. The endothermic peak $\left(\mathrm{T}_{\mathrm{m}}\right)$ found in the $\mathrm{HG}_{\mathrm{B}} \mathrm{DSC}$ thermogram was missed in $\mathrm{HG}_{\mathrm{NT}}$, confirming the enhanced thermal stability of the polymer blocks within hybrid hydrogels [39], while the electrical resistance was significantly decreased from values higher than $10^{12} \Omega \mathrm{cm}^{-1}\left(\mathrm{HG}_{\mathrm{B}}\right)$ to $7.010^{10} \Omega \mathrm{cm}^{-1}\left(\mathrm{HG}_{\mathrm{NT}}\right)$ [30].

\subsection{Sorption Properties of Hybrid Hydrogels}

In the last decades, the huge demand for minimizing the wastewater discharges and mitigating the hazards of pollutants, indeed, carried on to the development of various techniques, including physical, chemical, and biological methods [40]. Each method shows advantages or disadvantages depending on different factors such as dye chemical features, dye concentration, presence of additional impurities, cost of the process [41]. Here, we aim to explore the key advantage of adsorption methods, defined by the United States Environmental Protection Agency as one of the most excellent and best wastewater treatment techniques [42], by coupling the surface properties of CNT, the water affinity and 
eco-compatibility of acrylate hydrogels with the possibility to affect the sorbent properties by applying an external electric field. Moreover, such materials can open new opportunities for a multi-technique approach: when formulated into hydrogel films, they can be also used in membrane filtration process, another efficient and economically effective approach for wastewater remediation [43], while the intrinsic electrical and photothermal properties of $\mathrm{CNT}$, together with the possibility to decorate their surface with suitable catalysts, can open the possibility to use the hybrid hydrogel as a substrate for chemical methods [44].

In our previous work, the ability of $\mathrm{HG}_{\mathrm{NT}}$ hybrid materials to modulate the release of ionic drugs upon application of an external electric field was evaluated and ascribed to the peculiar physic-chemical features of either MWCNT and Gel. Here, based on the scientific evidence reporting the applicability of hybrid materials with similar properties to environmental remediation $[45,46]$, we aim to investigate a further extension of the applicability of such materials, exploiting their high affinity for dye adsorption from water solutions.

We extensively investigated the adsorption behavior using three different dyes, namely Methylene Blue (MB), Rhodamine B (RD), and Bengal Rose (BR), either in the presence or in the absence on an applied voltage (Figure 2).<smiles></smiles>

MB

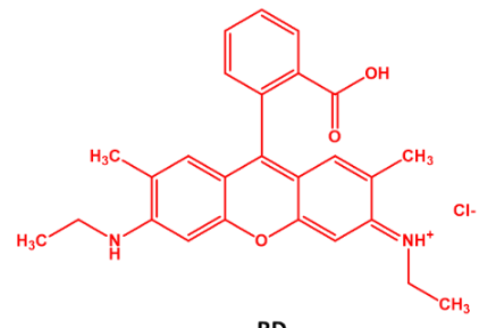

RD

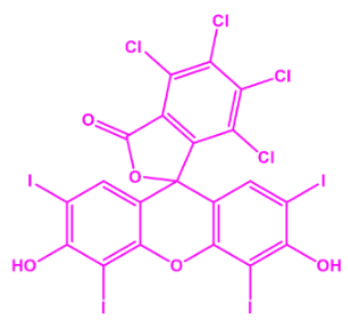

BR

Figure 2. Chemical structure of Methylene Blue (MB), Rhodamine B (RD), and Bengal Rose (BR) dyes.

$\mathrm{HG}_{\mathrm{NT}}$ swelling behavior was investigated in pure water media, obtaining water content percentage (WR) of $267 \pm 4 \%$, lower than that recorded for the blank $\left(\mathrm{HG}_{\mathrm{B}}\right)$ hydrogel samples $(317 \pm 3 \%$ ) because the presence of MWCNT was reported to reduce the hydrophilic behavior due to the hydrophobic $\pi-\pi$ CNT surface and enhance the mechanical strength hindering the swelling process [39]. Moreover, the determination of hydrogel porosity (33.24 and $24.67 \mathrm{~nm}$ for blank and hybrid hydrogels, respectively) by the empirical model consisting in the Kulkarni's version of Flory-Rehner theory [47], allowed hypothesizing of the ability of hybrid materials to adsorb organic molecules within the polymer network.

The schematic representation of hydrogel synthesis and sorption processes were depicted in Figure 3. 


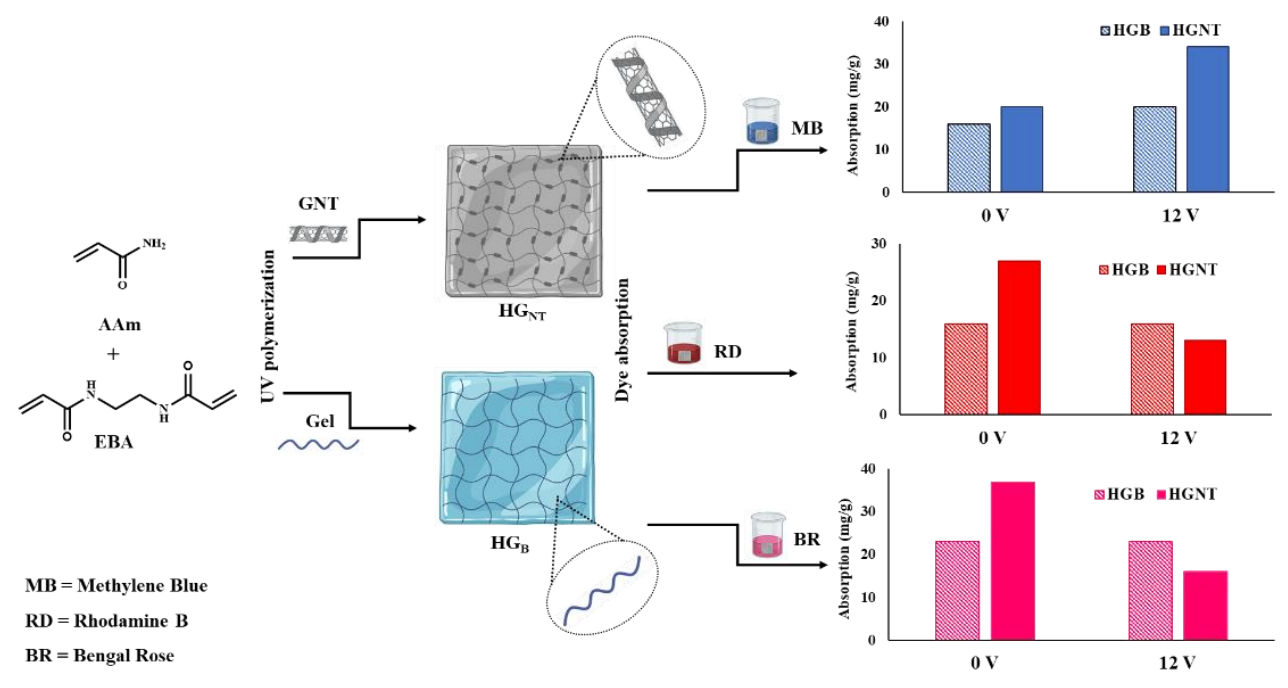

(a)

(b)

Figure 3. (a) Schematic representation of synthesis of hybrid hydrogels and (b) dye adsorption performance at different voltage conditions.

At $0 \mathrm{~V}$ conditions, it is clearly evident that the presence of CNT induces higher affinity of $\mathrm{HG}_{\mathrm{NT}}$ for any tested dyes, with the amount of adsorbed dye $\left(q_{\text {exp }}\right)$ being $19 \mathrm{mg} \mathrm{g}^{-1}(\mathrm{MB})$, $29 \mathrm{mg} \mathrm{g}^{-1}$ (RD), and $37 \mathrm{mg} \mathrm{g}^{-1}$ (BR) becoming 16, 15 and $23 \mathrm{mg} \mathrm{g}^{-1}$ in the case of $\mathrm{HG}_{\mathrm{B}}$ samples. These results are in agreement with the literature data claiming for higher loading efficiency of hybrid materials based on carbon nanostructures [48,49].

To calculate the thermodynamic behavior of dye adsorption process, we used an approach reported in the literature where the Gibbs free energy $\left(\Delta G^{\circ}\right)$ was described as a function of the $\frac{q_{e}}{C_{\rho}}\left(\mathrm{L} \mathrm{g}^{-1}\right)$ ratio [50]. The model allowed calculating $\Delta \mathrm{G}^{\circ}$, the enthalpy $\left(\Delta \mathrm{H}^{\circ}\right)$, entropy $\left(\Delta \mathrm{S}^{\circ}\right)$, and according to Equations (1) and (2):

$$
\begin{aligned}
\Delta G^{0} & =-R T \ln \left(K_{D}\right) \\
\ln \left(K_{D}\right) & =\frac{-\Delta H^{0}}{R T}+\frac{\Delta S^{0}}{R}
\end{aligned}
$$

Here, $R$ is the universal constant of gases $\left(8.314 \mathrm{~J} \mathrm{~mol}^{-1} \mathrm{~K}^{-1}\right), T$ the absolute temperature $(\mathrm{K})$, and $K_{D}$ the equilibrium constant calculated as follows (Equation (3)):

$$
K_{D}=1000 \times \frac{q_{e}}{C_{e}}
$$

The linear fits for the three dyes are depicted in Figure 4.

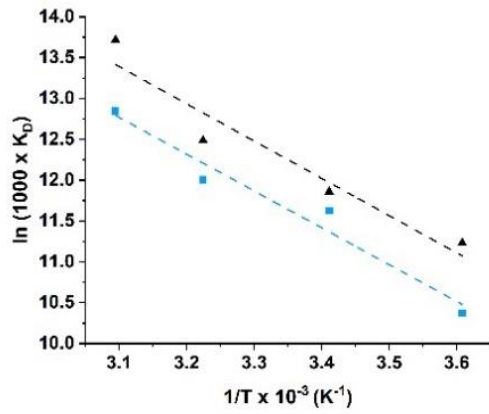

(a)

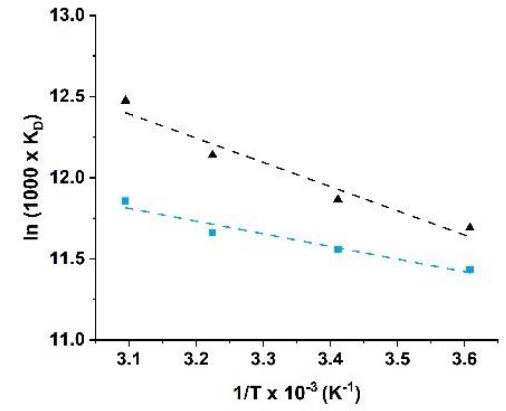

(b)

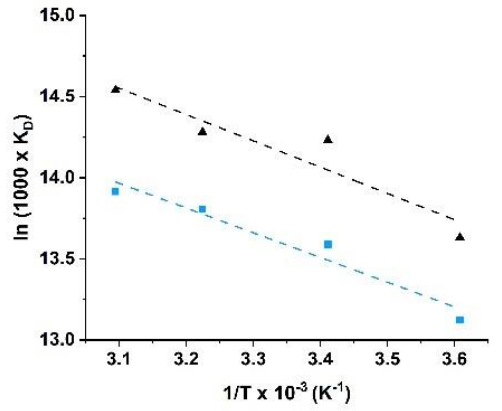

(c)

Figure 4. Relation of $\ln \left(1000 \times K_{D}\right)$ vs. $1 / \mathrm{T}$ to determine thermodynamic parameters for (a) MB, (b) RD, and (c) BR adsorption by $\mathrm{HG}_{\mathrm{B}}$ (blue lines) and $\mathrm{HG}_{\mathrm{NT}}$ (black lines). 
The evaluation of the obtained parameters (Table 1) showed that the adsorption processes were possible, spontaneous, and exothermic (negative $\Delta \mathrm{G}^{0}$ and $\Delta \mathrm{H}^{0}$ values) in all cases. The positive $\Delta S^{0}$ values indicated that the random collisions of dye molecules increase during the adsorption processes [50].

Table 1. Thermodynamic parameters for $\mathrm{MB}, \mathrm{RD}$, and $\mathrm{BR}$ adsorption by $\mathrm{HG}_{\mathrm{B}}$ and $\mathrm{HG}_{\mathrm{NT}}$.

\begin{tabular}{|c|c|c|c|c|c|c|c|c|c|c|c|c|c|c|}
\hline \multirow{2}{*}{ Dye } & \multicolumn{7}{|c|}{$\mathrm{HG}_{\mathbf{B}}$} & \multicolumn{7}{|c|}{$\mathrm{HG}_{\mathrm{NT}}$} \\
\hline & $\mathbf{R}^{2}$ & $\Delta G_{T_{1}}^{0}$ & $\Delta G_{T_{2}}^{0}$ & $\Delta G_{T_{3}}^{0}$ & $\Delta G_{T_{4}}^{0}$ & $\Delta \mathbf{H}^{0}$ & $\Delta S^{0}$ & $\mathbf{R}^{2}$ & $\Delta G_{T_{1}}^{0}$ & $\Delta G_{T_{2}}^{0}$ & $\Delta G_{T_{3}}^{0}$ & $\Delta G_{T_{4}}^{0}$ & $\Delta \mathbf{H}^{0}$ & $\Delta S^{0}$ \\
\hline MB & 0.9143 & -23.38 & -27.72 & -30.28 & -33.77 & -36.65 & 217.48 & 0.9283 & -25.31 & -28.28 & -31.49 & -36.05 & -37.11 & 223.97 \\
\hline RD & 0.9485 & -25.77 & -27.56 & -29.42 & -31.17 & -6.35 & 115.74 & 0.9514 & -26.35 & -28.29 & -30.63 & -32.79 & -12.14 & 138.42 \\
\hline $\mathrm{BR}$ & 0.9492 & -29.59 & -32.40 & -34.83 & -36.57 & -12.39 & 152.01 & 0.9098 & -30.73 & -33.94 & -36.03 & -38.22 & -13.18 & 159.21 \\
\hline
\end{tabular}

$\Delta \mathrm{G}^{0}\left(\mathrm{~kJ} \mathrm{~mol}^{-1}\right) ; \Delta \mathrm{H}^{0}\left(\mathrm{~kJ} \mathrm{~mol}^{-1}\right) ; \Delta \mathrm{S}^{0}\left(\mathrm{~J} \mathrm{~mol}^{-1} \mathrm{~K}^{-1}\right) ; \mathrm{T}_{1}=277.15 \mathrm{~K} ; \mathrm{T}_{2}=293.15 \mathrm{~K} ; \mathrm{T}_{3}=310.15 \mathrm{~K} ; \mathrm{T}_{4}=323.15 \mathrm{~K}$.

More in detail, in the tested temperature range, the lowest $\Delta \mathrm{G}^{0}$ were recorded for $\mathrm{BR}$, while the more exothermic process was found to be the MB adsorption, suggesting a different electronic behavior of the dyes.

Then, the effect of the application of an external electric field ( 6 and $12 \mathrm{~V})$ on the sorbent performance was explored, with the analysis of the variations (\%) of the $q_{\exp }$ values at $0 \mathrm{~V}$ $\left(q_{\text {exp }}^{0}\right)$ and applied voltage $\left(q_{\text {exp }}^{V}\right)$ being expressed according to the following Equation (4):

$$
\Delta Q^{V}=\left|\frac{q_{\exp }^{V}-q_{\text {exp }}^{0}}{q_{\exp }}\right| \times 100
$$

From data in Table 2, it is clear that no significant variations were recorded when $\mathrm{HG}_{\mathrm{B}}$ was used, while a modification in either nature or intensity of the sorbent/sorbate interactions can be hypothesized upon application of the electric field.

Table 2. $\mathrm{HG}_{\mathrm{B}}$ and $\mathrm{HG}_{\mathrm{NT}}$ sorption capacity $\left(\mathrm{mg} \mathrm{g}^{-1}\right)$ for $\mathrm{MB}, \mathrm{RD}$, and $\mathrm{BR}$ dyes at $\mathrm{0}, 6$, and 12 voltage conditions.

\begin{tabular}{|c|c|c|c|c|c|c|c|c|c|c|}
\hline \multirow{2}{*}{ Dye } & \multicolumn{5}{|c|}{$\mathrm{HG}_{\mathrm{B}}$} & \multicolumn{5}{|c|}{$\mathrm{HG}_{\mathrm{NT}}$} \\
\hline & $q_{\exp }^{0}$ & $q_{\exp }^{6}$ & $q_{\exp }^{12}$ & $\Delta Q^{6}$ & $\Delta Q^{12}$ & $q_{\exp }^{0}$ & $q_{\exp }^{6}$ & $q_{\exp }^{12}$ & $\Delta Q^{6}$ & $\Delta Q^{12}$ \\
\hline MB & $15.94 \pm 2.3$ & $17.22 \pm 2.2$ & $19.51 \pm 1.9$ & 8.03 & 22.39 & $19.72 \pm 1.9$ & $22.55 \pm 1.4$ & $33.45 \pm 2.4$ & 14.35 & 69.62 \\
\hline $\mathrm{RD}$ & $15.71 \pm 1.8$ & $15.67 \pm 2.5$ & $15.68 \pm 2.4$ & 0.25 & 0.19 & $28.93 \pm 2.0$ & $25.47 \pm 1.7$ & $13.06 \pm 1.6$ & 11.96 & 54.86 \\
\hline $\mathrm{BR}$ & $23.12 \pm 2.6$ & $23.01 \pm 2.6$ & $22.96 \pm 2.5$ & 0.48 & 0.69 & $36.75 \pm 2.3$ & $30.74 \pm 2.0$ & $15.85 \pm 2.0$ & 16.35 & 56.87 \\
\hline
\end{tabular}

In detail, an enhancement in $q_{\exp }^{V}$ occurred in the case of MB, whereas lower amount of $\mathrm{RD}$ and $\mathrm{BR}$ were retained. The analysis of data in Table 2 suggested that the electric field promotes the formation of negative charge on the hybrid hydrogels (due to the presence of both MWCNT and Gel), thus resulting in stronger interactions with cationic molecules (higher $q_{\exp }^{V}$ for MB dye) and reduced affinity for anionic molecules (lower RD adsorption). As far as the neutral BR dye is concerned, the reduced affinity is related to the induction of repulsive forces between polarized sorbent and sorbate molecules, with the latter also undergoing lactone ring opening and formation of negatively charged species [30,39]. These effects were more evident at 12 vs. $6 \mathrm{~V}$, while higher voltages (e.g., $24 \mathrm{~V}$ ) cannot be tested due to significant $(>15 \%)$ dyes degradation under these conditions.

When comparing the effectiveness of $\mathrm{HG}_{\mathrm{NT}}$ hybrid hydrogels in absorbing the dyes with the carbon nanomaterials-based systems available in the literature, it found that our system possessed similar adsorption capacity for BR (5.98 $\mathrm{mg} \mathrm{g}^{-1}$ [51] and $6.22 \mathrm{mg} \mathrm{g}^{-1}$ [52]), while considerable low affinity for MB (from 35.4 to $188.68 \mathrm{mg} \mathrm{g}^{-1}$ [53]) and RD dyes (from 55.56 to $\left.963.04 \mathrm{mg} \mathrm{g}^{-1}[54,55]\right)$. This can be ascribed to the peculiar characteristics of our systems where only $0.5 \%$ (by weight) of CNT are incorporated and their surface, being coated with Gel, is not fully available for dyes adsorption. Nevertheless, the feasibility of the synthetic strategy offers possibility to modify the hydrogel composition to enhance the sorbent performance, with the ability to modify the affinity for the different dyes upon 
application of the external voltage can open great opportunity for the development of effective sorbent materials.

\subsection{Isotherm Data Analysis}

For a proper understanding of an adsorption process (e.g., physical or chemical phenomena, mono- or multi- layered processes, homogeneous or heterogeneous sorption), and the design of effective systems with optimized parameters, the evaluation of relationships between adsorbent and adsorbate at equilibrium is of paramount importance [56,57]. Here, we investigated such relationship in the absence of electric stimulation and in the presence of the higher tested voltage $(12 \mathrm{~V})$ for either $\mathrm{HG}_{\mathrm{B}}$ or $\mathrm{HG}_{\mathrm{NT}}$ samples.

As expected, in all cases, an increased initial dye concentration was found to lead to increased adsorption capacity by virtue of the enhancement of the concentration gradient at the sorbent/sorbate interface (Figure 5) [58].

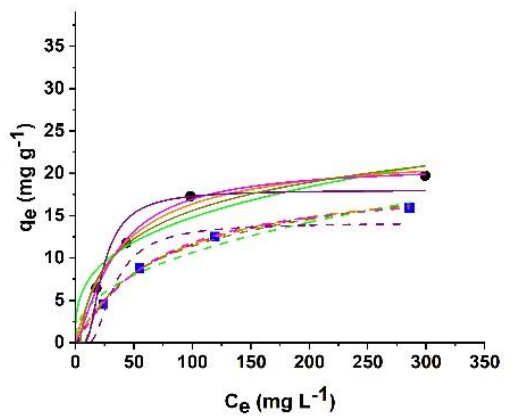

(a)

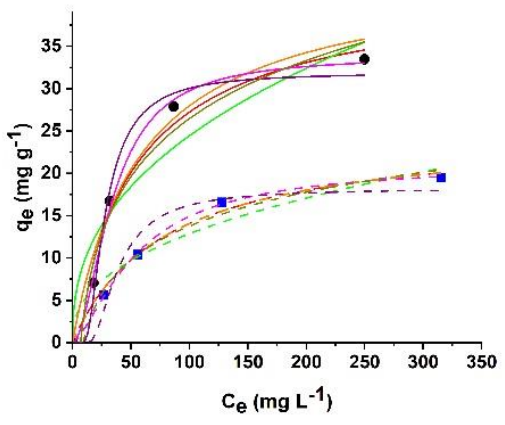

(d)

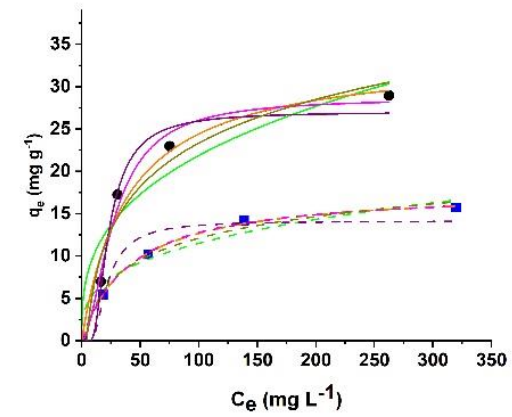

(b)

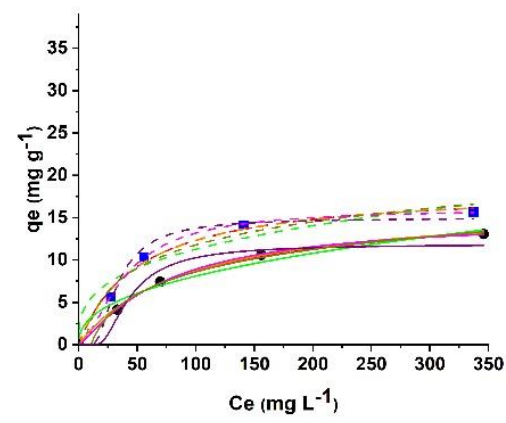

(e)

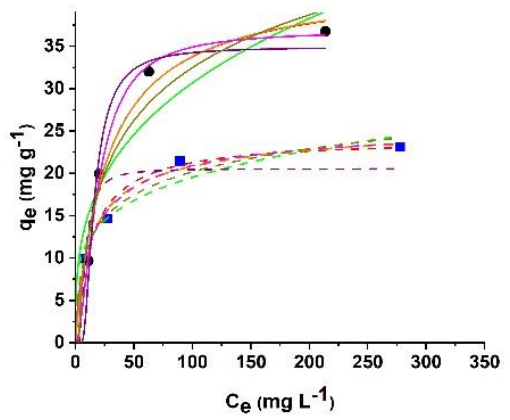

(c)

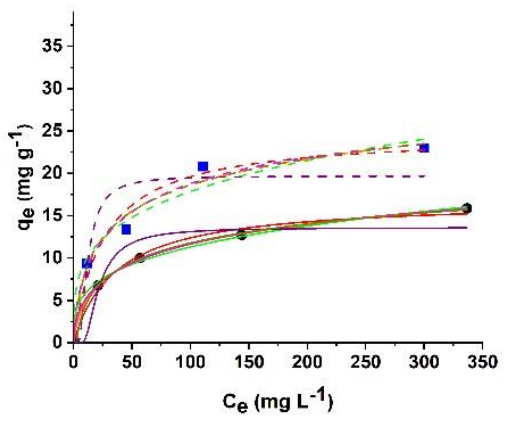

(f)

Figure 5. Langmuir (Red lines), Freundlich (Green lines), Red-Pet (Orange lines), Sips (Magenta lines), Dub-Rad (Purple lines), and Temkin (Dark Yellow lines) adsorption isotherms for (a,d) MB, (b,e) RD, and (c,f) BR dyes by HGNT (solid lines) and HGB (dashed lines) under (a-c) 0 and (d-f) $12 \mathrm{~V}$ conditions. (circles) and (squares) are the experimental data for $\mathrm{HG}_{\mathrm{NT}}$ and $\mathrm{HG}_{\mathrm{B}}$, respectively.

Among the different models proposed in the literature to describe such behavior, Langmuir, Freundlich, Redlich-Peterson, Sips, Dubinin-Radushkevich (Dub-Rad), and Temkin models (Equations (S1)-(S6) in Supplementary Materials) were used $[59,60]$. To avoid any distortions created in the original error distribution, Origin software was used for the application of the nonlinear optimization method instead of linear regressions [60].

The obtained parameters were collected in Table 3.

In the Langmuir model (Equation (S1)), firstly designed for describing gas-solid phase adsorptions, the dynamic adsorption and desorption equilibrium is described as the balance between the extent of available (adsorption favoured) and covered (desorption favoured) sorbent surface [61].

The model assumes the adsorption as an ideal monolayer process, with a fixed number of binding sites available on the surface of the adsorbent and no interaction between adsorbed species. As a consequence of this statement, when occupied by a sorbate molecule, 
no further adsorption can take place in a specific sorbent site [62]. In this model, the equilibrium parameter $R_{L}$ (Equation (S7) in Supplementary Materials) is the essential feature denoting the adsorption nature to be unfavourable $\left(R_{L}>1\right)$, linear $\left(R_{L}=1\right)$, favourable $\left(0<R_{L}<1\right)$, or irreversible $\left(R_{L}=0\right)$. On the other hand, heterogeneous sorbent systems are described by Freundlich model (Supplementary Materials Equation (S2)), with the heterogeneity factor $n_{F}$ indicating favourable $\left(0<1 / n_{F}<1\right)$, irreversible $\left(1 / n_{F}=1\right)$ or unfavourable $\left(1 / n_{F}>1\right)$ processes [62].

Table 3. Constants and variables of isotherm models for adsorption process.

\begin{tabular}{|c|c|c|c|c|c|c|c|c|c|c|c|c|c|}
\hline \multirow{3}{*}{\multicolumn{2}{|c|}{ Model/Parameter }} & \multicolumn{4}{|c|}{ MB } & \multicolumn{4}{|c|}{ RD } & \multicolumn{4}{|c|}{ BR } \\
\hline & & \multicolumn{2}{|c|}{$\mathrm{HG}_{\mathrm{B}}$} & \multicolumn{2}{|c|}{$\mathrm{HG}_{\mathrm{NT}}$} & \multicolumn{2}{|c|}{$\mathrm{HG}_{\mathrm{B}}$} & \multicolumn{2}{|c|}{$\mathrm{HG}_{\mathrm{NT}}$} & \multicolumn{2}{|c|}{$\mathrm{HG}_{\mathrm{B}}$} & \multicolumn{2}{|c|}{$\mathrm{HG}_{\mathrm{NT}}$} \\
\hline & & $0 \mathrm{~V}$ & $12 \mathrm{~V}$ & $0 \mathrm{~V}$ & $12 \mathrm{~V}$ & $0 \mathrm{~V}$ & $12 \mathrm{~V}$ & $0 \mathrm{~V}$ & $12 \mathrm{~V}$ & $0 \mathrm{~V}$ & $12 \mathrm{~V}$ & $0 \mathrm{~V}$ & $12 \mathrm{~V}$ \\
\hline \multirow{4}{*}{ Langmuir } & $\mathrm{R}^{2}$ & 0.9984 & 0.9893 & 0.9912 & 0.9688 & 0.9985 & 0.9874 & 0.9621 & 0.9981 & 0.9879 & 0.9650 & 0.9768 & 0.9874 \\
\hline & $q_{\max }$ & 20.19 & 25.01 & 23.01 & 42.17 & 18.00 & 18.51 & 33.91 & 16.59 & 24.18 & 24.69 & 42.64 & 16.87 \\
\hline & $k_{L}\left(10^{-2}\right)$ & 1.35 & 1.28 & 2.46 & 1.82 & 2.38 & 1.99 & 2.57 & 1.11 & 7.27 & 3.84 & 3.80 & 2.75 \\
\hline & $R_{L}$ & 0.16 & 0.16 & 0.09 & 0.12 & 0.10 & 0.11 & 0.09 & 0.18 & 0.03 & 0.06 & 0.06 & 0.08 \\
\hline \multirow{3}{*}{ Freundlich } & $\mathrm{R}^{2}$ & 0.9283 & 0.8665 & 0.8191 & 0.8004 & 0.8869 & 0.8116 & 0.8387 & 0.9285 & 0.9173 & 0.9354 & 0.9067 & 0.9867 \\
\hline & $k_{F}$ & 1.54 & 1.95 & 3.46 & 3.74 & 2.68 & 2.60 & 4.58 & 1.20 & 7.13 & 5.12 & 7.02 & 2.99 \\
\hline & $1 / n_{F}$ & 0.42 & 0.41 & 0.32 & 0.41 & 0.32 & 0.32 & 0.34 & 0.41 & 0.22 & 0.27 & 0.32 & 0.29 \\
\hline \multirow{5}{*}{ Red-Pet } & $\mathrm{R}^{2}$ & 0.9974 & 0.9839 & 0.9875 & 0.9477 & 0.9977 & 0.9811 & 0.9432 & 0.9969 & 0.9858 & 0.9636 & 0.9652 & 0.9994 \\
\hline & $k_{R P}$ & 0.27 & 0.32 & 0.57 & 0.76 & 0.43 & 0.37 & 0.87 & 0.18 & 2.24 & 1.90 & 1.62 & 1.14 \\
\hline & $\begin{array}{c}\alpha_{R P} \\
\left(10^{-2}\right)\end{array}$ & 1.34 & 1.28 & 2.46 & 1.72 & 2.38 & 1.98 & 2.57 & 1.09 & 12.88 & 18.87 & 3.80 & 21.75 \\
\hline & $g$ & 0.90 & 0.75 & 0.86 & 0.58 & 0.06 & 0.80 & 0.34 & 0.88 & 0.06 & 0.84 & 0.22 & 0.80 \\
\hline & $q_{R P}$ & 20.22 & 24.98 & 23.15 & 44.11 & 18.07 & 18.70 & 33.89 & 16.47 & 17.40 & 10.07 & 42.60 & 5.24 \\
\hline \multirow{4}{*}{ Sips } & $\mathrm{R}^{2}$ & 0.9994 & 0.9989 & 0.9969 & 0.9939 & 0.9981 & 0.9995 & 0.9747 & 0.9994 & 0.9894 & 0.9691 & 0.9970 & 0.9988 \\
\hline & $q_{\max }$ & 18.62 & 21.13 & 21.00 & 33.86 & 17.59 & 16.07 & 28.67 & 15.07 & 26.36 & 31.60 & 36.87 & 26.79 \\
\hline & $k_{S}\left(10^{-2}\right)$ & 0.86 & 0.27 & 0.93 & 0.15 & 2.01 & 0.25 & 0.27 & 0.59 & 11.86 & 8.57 & 0.57 & 7.16 \\
\hline & $n_{S}$ & 1.15 & 1.47 & 1.33 & 1.85 & 1.06 & 1.63 & 1.78 & 1.19 & 0.76 & 0.62 & 1.75 & 0.52 \\
\hline \multirow{4}{*}{ Dub-Rad } & $\mathrm{R}^{2}$ & 0.9202 & 0.9450 & 0.9369 & 0.9826 & 0.9285 & 0.9810 & 0.9771 & 0.9397 & 0.8759 & 0.8833 & 0.9818 & 0.9026 \\
\hline & $q_{\max }$ & 14.16 & 18.19 & 18.02 & 31.88 & 14.14 & 14.95 & 27.02 & 11.87 & 20.35 & 19.68 & 34.93 & 13.59 \\
\hline & $\beta_{D R}$ & 0.35 & 0.48 & 0.17 & 0.25 & 0.16 & 0.35 & 0.17 & 0.60 & 0.02 & 0.05 & 0.08 & 0.15 \\
\hline & $E$ & 1.19 & 1.02 & 1.70 & 1.42 & 1.79 & 1.20 & 1.71 & 0.91 & 4.56 & 3.20 & 2.46 & 1.82 \\
\hline \multirow{3}{*}{ Temkin } & $\mathrm{R}^{2}$ & 0.9977 & 0.9839 & 0.9732 & 0.9647 & 0.9890 & 0.9710 & 0.9480 & 0.9967 & 0.9835 & 0.9759 & 0.9528 & 0.9992 \\
\hline & $A_{T}$ & 0.12 & 0.11 & 0.26 & 0.14 & 0.26 & 0.20 & 0.23 & 0.10 & 1.69 & 0.64 & 0.37 & 0.38 \\
\hline & $B$ & 4.59 & 0.48 & 4.81 & 9.90 & 3.70 & 3.96 & 7.45 & 3.81 & 3.93 & 4.46 & 9.00 & 3.24 \\
\hline
\end{tabular}

Better mathematical fits were recorded for Langmuir model as per higher $\mathrm{R}^{2}$ values in Table 3, clearly suggesting a predominant surface adsorption mechanism, with heterogenous contribution of Freundlich model being evident in the case of BR adsorption by $\mathrm{HG}_{\mathrm{NT}}$ under $12 \mathrm{~V}$ conditions ( $\mathrm{R}^{2}$ of 0.9867$)$.

Favourable sorption processes are evoked by both models $\left(0<R_{L}<1\right.$ and $\left.0<1 / n_{F}<1\right)$, proving the suitability of the hybrid hydrogels as effective sorbent materials. Moreover, the variation of $q_{\max }$ values in the Langmuir model upon application of the external voltage clearly showed the electro-responsivity of the hybrid hydrogels: an increase $q_{\max }$ is recorded when $\mathrm{MB}$ is used as dye, while an opposite trend occurred for RD and BR. As expected, the variation of $q_{\max }$ by the electric field is the result of the incorporation of MWCNT, since the extent of $q_{\max }$ variation is significantly higher in $\mathrm{HG}_{\mathrm{NT}}$ than in $\mathrm{HG}_{\mathrm{B}}$ cases. The Freundlich model is consistent with this statement, since the $k_{F}$ parameter values showed a similar behavior.

Since a monolayer sorption process is assumed, we can use the maximum dye adsorption to estimate the Apparent Specific Surface Area (SSA) of $\mathrm{HG}_{\mathrm{B}}$ and $\mathrm{HG}_{\mathrm{NT}}$ according to the Equation (S8) in the Supplementary Materials [63]. Literature data suggested that the areas covered per dye molecule are $1.3810^{-18} \mathrm{~m}^{2}$ for MB [63], $3.4810^{-19} \mathrm{~m}^{2}$ for RD [64], and $5.010^{-19} \mathrm{~m}^{2}$ for BR [65], resulting in SSA of 13059 (MB), 3329 (RD), and $6953(\mathrm{BR}) \mathrm{m}^{2} \mathrm{~g}^{-1}$ in the case of $\mathrm{HG}_{\mathrm{B}}$, and $16052(\mathrm{MB}), 5778$ (RD), and 11061 (BR) $\mathrm{m}^{2} \mathrm{~g}^{-1}$ 
when $\mathrm{HG}_{\mathrm{NT}}$ is used as sorbent. As expected, different values were obtained for the three dyes, since this evaluation is based on the maximum adsorption capacity, and thus is strongly affected by the different dyes to sorbent interactions. In our conditions, since MB covers the wide hydrogel surface, we can use the value obtained for this dye to estimate the SSA of hydrogels. Moreover, this estimation can be used as a direct evidence of the different sorbate to sorbent affinity, and helps in understanding the effect of applying the external voltage. Low variations were indeed recorded for $\mathrm{HG}_{\mathrm{B}}$ samples (SSA of 15932 (MB), 3302 (RD), and 6919 (BR) $\mathrm{m}^{2} \mathrm{~g}^{-1}$ ), while a significant enhancement in the $\mathrm{HG}_{\mathrm{NT}}$ SSA was obtained for MB sorption process $\left(27339 \mathrm{~m}^{2} \mathrm{~g}^{-1}\right)$ as a result of both the higher swelling degree of the hydrogel matrix (341\%) and the enhanced sorbate to sorbent affinity. A totally different behavior was recorded for the RD and BR sorption processes, where the decrease of the apparent SSA to 2780 (RD) and $4816 \mathrm{~m}^{2} \mathrm{~g}^{-1}$ (BR) was assigned to the insurgence of the repulsion forces between hybrid hydrogels and dyes, and not yet to the changes in hydrogels water affinity.

More information can be obtained by the application of Red-Pet model (Supplementary Materials Equation (S3)), often used as a compromise between Freundlich and Langmuir systems in accordance to the $g$ value lying between 0 and 1: a Langmuir isotherm is indeed obtained when $g=1$, while $\alpha_{R P} C_{e}^{g} \gg 1$ accounts for the Freundlich model [66]. Data in Figure 5 (orange lines) and Table 3 proved the suitability of this model in describing the adsorption of all dyes, with $R^{2}>0.94$ in all experimental conditions. From the analysis of the sorption capacity $q_{R P}$ (calculated by Equation (S9) in Supplementary Materials) is evident the higher affinity of hybrid hydrogels for all the tested dyes at $0 \mathrm{~V}$ conditions (higher $q_{R P}$ for $\mathrm{HG}_{\mathrm{NT}}$ vs. $\mathrm{HG}_{\mathrm{B}}$ ) [60]. Moreover, $q_{R P}$ helps in understanding the effect of the external voltage on the sorption efficiency of the samples. By comparing the value obtained for $\mathrm{HG}_{\mathrm{NT}}$ at $12 \mathrm{vs} .0 \mathrm{~V}$ conditions, a significant enhancement of sorption capacity was recorded for $\mathrm{MB}$, while the opposite trend was shown for $\mathrm{RD}$ and $\mathrm{BR}$ dyes, suggesting that the electronic perturbation of the MWCNT surface induced by the electric field increased the affinity for $\mathrm{MB}$ while hindered the interactions with the other two dyes. As expected, the variations recorded for $\mathrm{HG}_{\mathrm{B}}$ samples were less significant.

The Sips isotherm (Figure 5, Magenta lines) is another three-parameter model applied for describing the sorption process (Supplementary Materials Equation (S4)) as a combination of Langmuir and Freundlich ones [60]. Here, $n_{s}=1$ and $C_{e}$ (or $k_{s}$ ) close to 0 result in Langmuir and Freundlich equations, respectively. The calculated parameters (Table 3) showed that the sorption process is intermediate between the two limit models, approaching to Langmuir, especially for $\mathrm{MB}$ and $\mathrm{RD}$ dyes, while in the case of $\mathrm{BR}$, a more relevant contribution of Freundlich model was recorded as per lower $n_{s}$ values. This is in agreement with the data obtained from Supplementary Materials Equation (S2) (Table 3), showing $R^{2}>0.90$ in the case of $B R$ sorption from both $H_{B}$ and $H_{\mathrm{NT}}$.

Dub-Rad (Supplementary Materials Equation (S5)) is a more general model, not assuming homogeneous or heterogeneous surfaces, and useful to understand the nature (chemical vs. physical) of the adsorption process. In this model, the key determining parameter is the apparent energy of adsorption mechanism (E, Equation (S11) in Supplementary Materials), indicating chemical $\left(8 \mathrm{~kJ} \mathrm{~mol}^{-1}<\mathrm{E}<16 \mathrm{~kJ} \mathrm{~mol}^{-1}\right)$ or physical $(\mathrm{E}<$ $8 \mathrm{~kJ} \mathrm{~mol}^{-1}$ ) process [60]. The fitting of the experimental data and the related parameters was depicted in Figure 5 (Purple lines) and Table 3. The model was found to be suitable for describing the adsorption of the three dyes by both blank and hybrid hydrogels $\left(R^{2}>0.87\right.$, see Table 3), with the obtained E values claiming for a predominant physical phenomenon in all cases.

Finally, the Temkin model (Supplementary Materials Equation (S6)) was applied to the experimental data (Figure 5, Dark Yellow lines). As seen for Dub-Rad isotherm, this model focus on the free energy of the sorption process (B), which is assumed to be a function of surface coverage and can be expressed according to the Equation (S12) in Supplementary Materials. Temkin parameters (Table 3) were consistent with both Dub-Rad 
and thermodynamic models, since it is reported that positive B values indicated a physical and exothermic sorption process [60].

\subsection{Kinetic Data Analysis}

Adsorption rate at 0 and $12 \mathrm{~V}$ conditions was also investigated in detail, showing that the concentration gradient at the sorbent/sorbate interface progressively hinders more of dye molecules to enter the adsorbent with time, thus resulting in fast adsorption at the first experimental times, followed by a slower rate eventually attaining equilibrium. At the first experimental time, a large number of empty sites were available for dyes adsorption, while the repulsive forces between the dye molecules on sorbent surface makes the remaining sites difficult to be occupied [45].

The adsorption rate was investigated by six models describing pseudo-first order, pseudo second-order, Avrami, fractional power, intraparticle diffusion, and Elovich kinetics (Equations (S13)-(S18) in Supplementary Materials). To evaluate the fitting between experimental data, we used the $\mathrm{R}^{2}$ and the $\chi^{2}$ values, the latter being calculated according to Equation (S19) in Supplementary Materials.

Primarily, pseudo-first order (Supplementary Materials Equation (S13)) [67] and pseudo-second order (Supplementary Materials Equation (S14)) models [68] were considered (Figure 6, Red and Green lines). Supplementary Materials Equation (S13) describes the adsorption rate based on the adsorption capacity, while Supplementary Materials Equation (S14) claims for sorption process with the involvement of electron sharing and/or exchange between the sorbent and the sorbate [69].

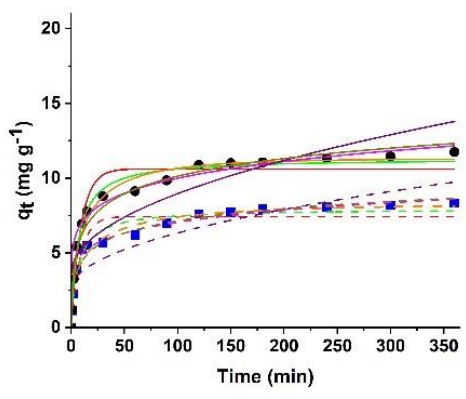

(a)

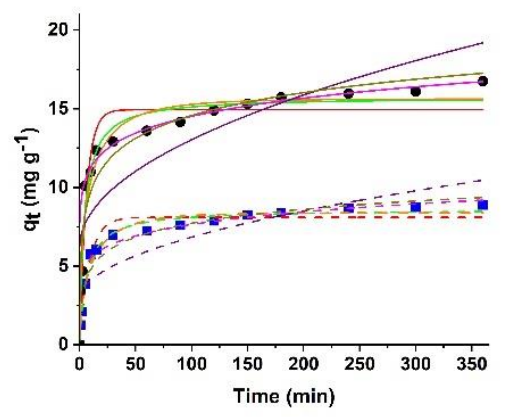

(d)

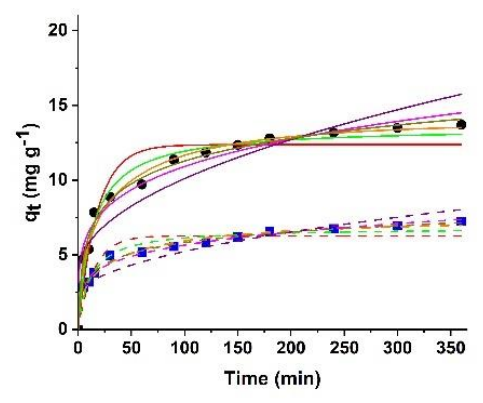

(b)

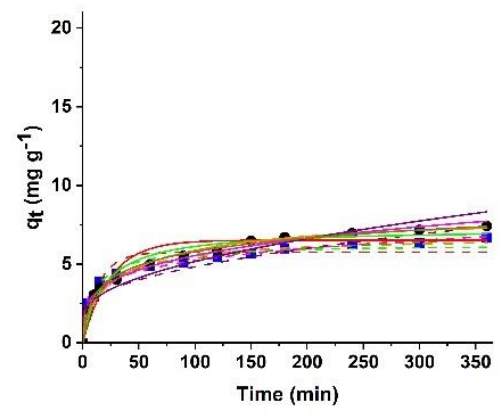

(e)

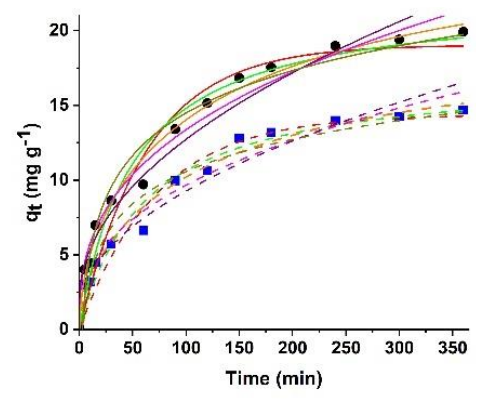

(c)

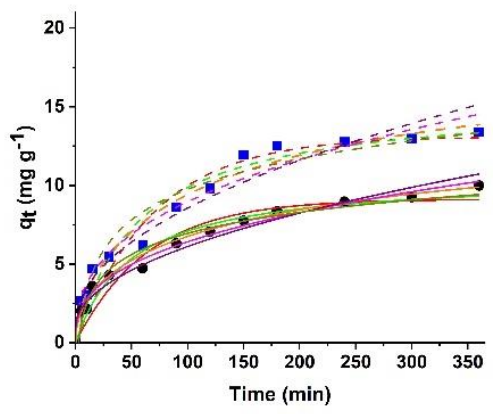

(f)

Figure 6. Pseudo-first order (Red lines), Pseudo-second order (Green lines), Avrami (Orange lines), Fractional Power (Magenta lines), Intraparticle Diffusion (Purple lines), and Elovich (Dark Yellow lines) kinetics models for (a,d) MB, $(\mathbf{b}, \mathbf{e}) \mathrm{RD}$, and (c,f) BR dyes by $\mathrm{HG}_{\mathrm{NT}}$ (solid lines) and $\mathrm{HG}_{\mathrm{B}}$ (dashed lines) under (a-c) 0 and (d-f) $12 \mathrm{~V}$ conditions. (circles) and (squares) are the experimental data for $\mathrm{HG}_{\mathrm{NT}}$ and $\mathrm{HG}_{\mathrm{B}}$, respectively.

In our experimental conditions, a better fitting was recorded when Equation (S14) was applied to $\mathrm{MB}$ and $\mathrm{RD}$ adsorption, as per both higher $\mathrm{R}^{2}$ and lower $\chi^{2}$ values (Table 4).

The comparison of the results of pseudo-first and pseudo-second order models suggested that, although the sorption process is predominantly physical, the electronic be- 
havior of both hydrogel surface and dye molecules plays a crucial role in determining the sorbent/sorbate interactions. This can be attributed to the properties of carbon nanostructures and is consistent with literature data showing that pseudo-second order kinetics well described the adsorption of RD and MB dyes on graphene nanosheets and CNT, respectively $[45,70]$. A different behavior was obtained in the case of $B R$, where, although pseudo-second model kinetics possessed the higher $\mathrm{R}^{2}$ values, the better fitting between $q_{\text {exp }}$ and $q_{e}$ (lower $\chi^{2}$ values) was obtained for the pseudo-first order model, suggesting a lower involvement of electronic perturbation due to the absence of electrostatic charge on the dye molecule.

Table 4. Parameters of the kinetics models applied to the adsorption processes.

\begin{tabular}{|c|c|c|c|c|c|c|c|c|c|c|c|c|c|}
\hline \multirow{3}{*}{\multicolumn{2}{|c|}{ Model/Parameter }} & \multicolumn{4}{|c|}{ MB } & \multicolumn{4}{|c|}{ RD } & \multicolumn{4}{|c|}{ BR } \\
\hline & & \multicolumn{2}{|c|}{$\mathrm{HG}_{\mathrm{B}}$} & \multicolumn{2}{|c|}{$\mathrm{HG}_{\mathrm{NT}}$} & \multicolumn{2}{|c|}{$\mathrm{HG}_{\mathrm{B}}$} & \multicolumn{2}{|c|}{$\mathrm{HG}_{\mathrm{NT}}$} & \multicolumn{2}{|c|}{$\mathrm{HG}_{\mathrm{B}}$} & \multicolumn{2}{|c|}{$\mathrm{HG}_{\mathrm{NT}}$} \\
\hline & & $0 \mathrm{~V}$ & $12 \mathrm{~V}$ & $0 \mathrm{~V}$ & $12 \mathrm{~V}$ & $0 \mathrm{~V}$ & $12 \mathrm{~V}$ & $0 \mathrm{~V}$ & $12 \mathrm{~V}$ & $0 \mathrm{~V}$ & $12 \mathrm{~V}$ & $0 \mathrm{~V}$ & $12 \mathrm{~V}$ \\
\hline \multirow{4}{*}{$\begin{array}{l}\text { Pseudo- } \\
\text { First }\end{array}$} & $\mathrm{R}^{2}$ & 0.9238 & 0.9654 & 0.9500 & 0.9429 & 0.9001 & 0.9050 & 0.9217 & 0.9001 & 0.9528 & 0.9386 & 0.9436 & 0.9226 \\
\hline & $q_{e}$ & 7.43 & 8.10 & 10.62 & 14.94 & 6.27 & 5.75 & 12.37 & 6.52 & 14.37 & 13.11 & 19.04 & 9.13 \\
\hline & $k_{1}\left(10^{-2}\right)$ & 11.57 & 11.31 & 10.87 & 16.43 & 6.71 & 7.21 & 5.60 & 4.10 & 1.38 & 1.43 & 1.57 & 1.55 \\
\hline & $\chi^{2}$ & 10.63 & 7.61 & 11.76 & 21.72 & 15.22 & 14.98 & 14.26 & 12.45 & 0.63 & 0.58 & 4.04 & 8.05 \\
\hline \multirow{4}{*}{$\begin{array}{l}\text { Pseudo- } \\
\text { Second }\end{array}$} & $\mathrm{R}^{2}$ & 0.9699 & 0.9881 & 0.9845 & 0.9740 & 0.9592 & 0.9622 & 0.9739 & 0.9639 & 0.9667 & 0.9561 & 0.9682 & 0.9573 \\
\hline & $q_{e}$ & 7.94 & 8.61 & 11.32 & 15.76 & 6.82 & 6.24 & 13.56 & 7.27 & 17.17 & 15.45 & 22.26 & 10.60 \\
\hline & $k_{2}\left(10^{-2}\right)$ & 1.95 & 1.82 & 1.33 & 1.49 & 1.30 & 1.52 & 0.54 & 0.73 & 0.09 & 0.11 & 0.09 & 0.19 \\
\hline & $\chi^{2}$ & 1.81 & 0.83 & 1.53 & 6.16 & 2.64 & 3.10 & 0.13 & 0.31 & 36.38 & 27.73 & 24.60 & 3.53 \\
\hline \multirow{5}{*}{ Avrami } & $\mathrm{R}^{2}$ & 0.9711 & 0.9762 & 0.9702 & 0.9614 & 0.9756 & 0.9762 & 0.9889 & 0.9837 & 0.9972 & 0.9732 & 0.9869 & 0.9940 \\
\hline & $q_{e}$ & 8.27 & 11.31 & 8.38 & 15.63 & 7.34 & 6.55 & 13.89 & 7.70 & 17.83 & 16.70 & 24.89 & 13.47 \\
\hline & $k_{A}\left(10^{-2}\right)$ & 5.59 & 8.64 & 6.90 & 11.74 & 2.88 & 3.37 & 3.08 & 1.92 & 0.77 & 0.73 & 0.72 & 0.49 \\
\hline & $n$ & 0.47 & 0.63 & 0.54 & 0.54 & 0.47 & 0.50 & 0.54 & 0.55 & 0.62 & 0.59 & 0.57 & 0.50 \\
\hline & $\chi^{2}$ & 0.03 & 3.02 & 1.64 & 7.98 & 0.13 & 0.27 & 0.26 & 1.04 & 55.89 & 65.82 & 99.32 & 90.23 \\
\hline \multirow{5}{*}{$\begin{array}{c}\text { Fractional } \\
\text { power }\end{array}$} & $\mathrm{R}^{2}$ & 0.9795 & 0.9771 & 0.9915 & 0.9662 & 0.9744 & 0.9689 & 0.9514 & 0.9824 & 0.9599 & 0.9524 & 0.9701 & 0.9812 \\
\hline & $q_{e}$ & 8.29 & 9.08 & 11.87 & 16.36 & 7.36 & 6.71 & 14.51 & 7.73 & 15.92 & 14.53 & 21.39 & 10.26 \\
\hline & $k_{p}$ & 3.76 & 4.26 & 5.36 & 8.04 & 2.17 & 2.07 & 3.91 & 1.67 & 1.61 & 1.57 & 2.46 & 1.18 \\
\hline & $V$ & 0.13 & 0.13 & 0.14 & 0.12 & 0.21 & 0.20 & 0.22 & 0.26 & 0.39 & 0.38 & 0.37 & 0.37 \\
\hline & $\chi^{2}$ & 0.01 & 0.43 & 0.15 & 0.91 & 0.19 & 0.02 & 4.51 & 1.21 & 9.67 & 9.02 & 10.19 & 0.72 \\
\hline \multirow{5}{*}{$\begin{array}{l}\text { Intraparticle } \\
\text { Diffusion }\end{array}$} & $\mathrm{R}^{2}$ & 0.8008 & 0.7391 & 0.7662 & 0.8085 & 0.8338 & 0.8205 & 0.8336 & 0.8997 & 0.9550 & 0.9466 & 0.9559 & 0.9666 \\
\hline & $q_{e}$ & 9.59 & 10.40 & 13.61 & 19.08 & 8.03 & 7.37 & 15.74 & 8.32 & 16.55 & 15.15 & 22.39 & 10.72 \\
\hline & $k_{i}$ & 0.41 & 0.43 & 0.57 & 0.82 & 0.31 & 0.28 & 0.63 & 0.35 & 0.81 & 0.74 & 1.08 & 0.51 \\
\hline & $\mathrm{C}$ & 1.80 & 2.25 & 2.78 & 3.53 & 2.10 & 1.99 & 3.80 & 1.63 & 1.13 & 1.19 & 1.94 & 0.97 \\
\hline & $\chi^{2}$ & 16.87 & 22.18 & 25.72 & 28.72 & 7.64 & 6.40 & 26.63 & 9.71 & 21.19 & 20.72 & 27.24 & 5.07 \\
\hline \multirow{3}{*}{ Elovich } & $\mathrm{R}^{2}$ & 0.9782 & 0.9660 & 0.9766 & 0.9513 & 0.9927 & 0.9923 & 0.9900 & 0.9956 & 0.9085 & 0.9121 & 0.9555 & 0.9210 \\
\hline & $\alpha$ & 4.89 & 5.31 & 6.39 & 21.59 & 2.73 & 2.81 & 3.75 & 1.24 & 0.85 & 0.91 & 1.35 & 0.68 \\
\hline & $B$ & 0.84 & 0.78 & 0.58 & 0.48 & 0.96 & 1.06 & 0.46 & 0.79 & 0.36 & 0.42 & 0.26 & 0.57 \\
\hline
\end{tabular}

$q_{e}\left(\mathrm{mg} \mathrm{g}^{-1}\right) ; k_{1}\left(\min ^{-1}\right) ; k_{2}\left(\mathrm{~g} \mathrm{mg}^{-1} \min ^{-1}\right) ; k_{A}\left(\min ^{-1}\right), k_{p}\left(\mathrm{mg} \mathrm{g}^{-1} \min ^{-v}\right) ; k_{i}\left(\mathrm{mg} \mathrm{g}^{-1} \min ^{-1 / 2}\right) ; \alpha\left(\mathrm{mg} \mathrm{g}^{-1} \mathrm{~min}^{-1}\right) ; \beta\left(\mathrm{g} \mathrm{mg}^{-1}\right)$.

The whole of the above reported data suggested that the sorption mechanism is a complex phenomenon involving multiple kinetic orders that can change during sorbent/sorbate interactions [71]. Thus, we applied the Avrami kinetic model (Supplementary Materials Equation (S15)) to the experimental data, since the Avrami exponent $n$ is a clear indicator of the changes in the adsorption mechanism during the entire process [72]. As a result, a better fitting between experimental and theoretical data was reached in the case of $\mathrm{MB}$ and $\mathrm{RD}$, while for $\mathrm{BR}$, higher $\chi^{2}$ values suggested less variable sorption kinetics (Table 4). The fractional power model (Supplementary Materials Equation (S16)) agrees with this statement, as per similar trend in the recorded $\chi^{2}$ values, thus claiming for a similar nature of $\mathrm{MB} / \mathrm{RD}$ to hydrogels interactions, while different kinetics are involved in the case of BR (Table 4).

The application of intraparticle diffusion model (Supplementary Materials Equation (S17)) aims to elucidate the contribution of the diffusion of the dye molecules within the hydrogel network [58]. It was found that the sorption is mainly a surface phenomenon for the charged $\mathrm{MB}$ and $\mathrm{RD}$ dyes, while the diffusion is more involved in the BR sorption process 
(see $\mathrm{R}^{2}$ values in Table 4), although the higher $\chi^{2}$ values suggested that the phenomenon is mainly confined to the sorbent surface also in this case.

Finally, information about the correlation between the initial adsorption rate constant and rate constant at any stage of the process are given by the Elovich model (Supplementary Materials Equation (S18)), which can be considered an application of the Temkin isotherm to the analysis of the sorption rate [58]. The results (Table 4), clearly prove that the higher affinity of $\mathrm{HG}_{\mathrm{NT}}$ samples for all dyes at $0 \mathrm{~V}$ conditions (higher $\alpha$ values), as well as the electro-responsivity of the hybrid hydrogels. Upon application of the external voltage, indeed, a remarkable increase and decrease in $\alpha$ values are recorded for $\mathrm{MB}$ and $\mathrm{RD} / \mathrm{BR}$ sorption processes, respectively.

\subsection{Desorption Studies}

The reusability of an adsorbing matrix without significant loss of efficiency is a key important item when considering the potential industrial applications. Consequently, the operational stability of $\mathrm{HG}_{\mathrm{NT}}$ and $\mathrm{HG}_{\mathrm{B}}$ samples was evaluated in a repeated batch process. Considering the chemical structure of dyes molecules (Figure 1) and the composition of sorbent hydrogels, after each cycle, hydrogel films were treated with buffered solution at different $\mathrm{pH}$ (from 3 to 9) to remove the adsorbed dyes (Figure 7).

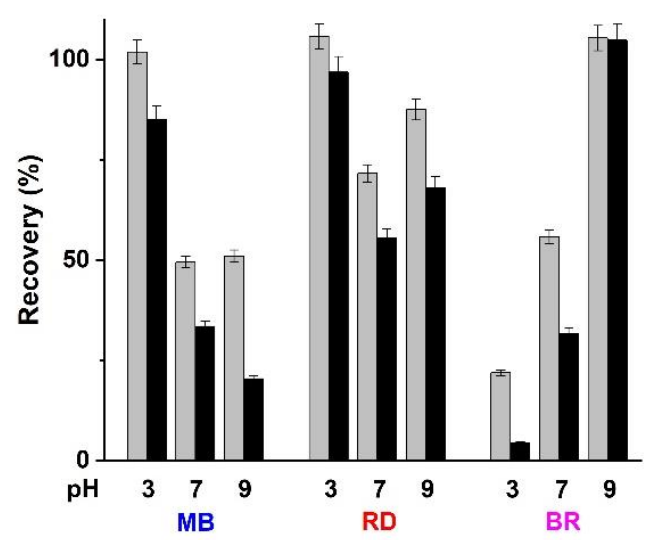

Figure 7. Dyes recovery (\%) after $24 \mathrm{~h}$ treatment of loaded $\mathrm{HG}_{\mathrm{B}}$ (grey bar) and $\mathrm{HG}_{\mathrm{NT}}$ (black bar) with water solutions at different $\mathrm{pH}$ values.

It is clearly evident that the variation of $\mathrm{pH}$ greatly affected the dye to hydrogels interactions, and that the recovery values are higher in $\mathrm{HG}_{\mathrm{B}}$ than $\mathrm{HG}_{\mathrm{NT}}$ case, due to the stronger affinity of MWCNT for all the tested dyes. At acidic $\mathrm{pH}$, a marked decrease in the retention capacity was observed for $\mathrm{MB}$ and $\mathrm{RD}$ dyes, since the protonation of the $\mathrm{COOH}$ functionalities of hydrogel surface reduced the electrostatic interactions with the cationic portions of the two dyes. This effect is even more evident in RD case possessing $\mathrm{COOH}$ groups as well. For MB, recovery values below $50 \%$ were recorded at neutral and alkaline $\mathrm{pH}$ values, as a consequence of the presence of strong dye to hydrogel electrostatic interactions in these conditions.

A different behavior was observed when the BR recovery profiles were investigated. Here, the highest recovery was obtained at $\mathrm{pH} 9$, while a very low amount of dye was detected in the acidic washing media. This can be related to the disruption of hydrogen bonding under alkaline conditions, as well as to the insurgence of electrostatic repulsions between the $\mathrm{COO}^{-}$groups on hydrogel surface and the opened lactone ring of the dye molecule.

Furthermore, since the application of the external voltage was found to significantly decrease the dye to hydrogel affinity in the case of RD and BR, we explored the possibility to use the electric field as desorption agent for these dyes. A fast and complete dyes removal was observed, with the removal (\%) reaching values of $97 \pm 2 \%$ in 1 and $1.5 \mathrm{~h}$ for RD and BR, respectively. These data were in agreement with either the isothermal and 
kinetic adsorption studies of our previous work dealing with the release of therapeutic agents from the same hydrogel system [30]. In detail, a higher affinity of the hydrogel matrix for BR (higher $q_{\exp }^{0}$ and kinetic constants) resulted in slower desorption under $12 \mathrm{~V}$ condition. Moreover, the same hydrogel was found to totally release the anionic diclofenac sodium after $50 \mathrm{~min}$, thus suggesting that a similar phenomenon occurred in the case of $\mathrm{RD}$ and BR. Interestingly, the adsorption capability was found to remain almost unchanged $(p>0.05)$ after five repeated sorption cycles, proving the suitability of the proposed systems as effective adsorbing element for industrial application in wastewater treatment. The effectiveness of $\mathrm{HG}_{\mathrm{NT}}$ as sorbent materials was also highlighted by comparing the key physic-chemical parameters, e.g., surface appearance and morphology (Figures S2 and S3 in the Supplementary Materials), FT-IR (Figure S1 in the Supplementary Materials) and Raman (Figure S4 in the Supplementary Materials) patterns, as well as electric and thermal properties) before and after the sorption cycles. It was found that when all adsorbed dyes were removed in the proper $\mathrm{pH}$ or electric conditions, such parameters (no new peaks in the FT-IR patterns, $I_{D} / I_{G}$ value of 1.77 , electrical resistance of $7.210^{10} \Omega \mathrm{cm}^{-1}$, absence of any endothermic peak in the DSC analyses) were unchanged as expected for highly crosslinked acrylic polymer networks.

\section{Materials and Methods}

\subsection{Synthesis of MWCNT and $H G_{N T}$}

MWCNT were synthesized by aerosol assisted chemical vapour deposition method according to the literature [36] The purification procedure involved the thermal treatment of as-grown material at $450{ }^{\circ} \mathrm{C}$ in air for $1 \mathrm{~h}$ with hydrochloric acid.

For the synthesis of $\mathrm{HG}_{\mathrm{NT}}$, MWCNT (1.0 mg) were firstly dispersed in a Gelatin (Gel) solution $(15 \mathrm{mg}, 2.0 \mathrm{~mL})$ by a cup-horn high intensity SONOPULS ultrasonic homogenizer (BANDELIN electronic, Berlin, Germany) with a cylindrical tip operating at 70\% amplitude. Then, after the addition of AAm $(85 \mathrm{mg})$ and EBA $(100 \mathrm{mg})$, the solution was purged with $\mathrm{N}_{2}$ for $20 \mathrm{~min}$, placed between two $5.0 \times 5.0 \mathrm{~cm}^{2}$ glass plates, separated with a Teflon spacer $(0.6 \mathrm{~mm})$ and brought together by binder clips, and photopolymerized in the presence of Irgacure 2959 as photoinitiator under a Philips HPK 125 high pressure mercury lamp operating at $500 \mathrm{~mW} \mathrm{~cm}^{-2}$ and $275 \mathrm{~nm}$ wavelength (Philips, Amsterdam, The Netherlands). $\mathrm{HG}_{\mathrm{NT}}$ samples were washed with distilled water to remove unreacted species and finally dried under vacuum at $40{ }^{\circ} \mathrm{C}$ for $12 \mathrm{~h}$ [30].

Blank hydrogels $\mathrm{HG}_{\mathrm{B}}$ were synthesized as reported without adding MWCNT in the pre-polymerization mixture.

All chemicals were from Merck/Sigma Aldrich, Darmstadt, Germany.

\subsection{Characterization Procedure}

The scanning electron microscopy analyses were run on a NOVA NanoSEM 200 (0-30 kV) (Thermo Fisher Scientific, Hillsboro, OR, USA). Samples were cut into thin slices by ultra-microtome cutting technique and deposited onto self-adhesive, conducting carbon tapes (Plano GmbH, Wetzlar, Germany).

The stability of the MWCNT dispersion into the polymerization feed was determined by dynamic light scattering analysis using a 90 Plus Particle Size Analyzer (Brookhaven Instruments Corp, Holtsville, NY, USA) at $25.0 \pm 0.1{ }^{\circ} \mathrm{C}$ by measuring the autocorrelation function at $90^{\circ}$. The laser was operating at $658 \mathrm{~nm}$.

The Raman spectra were recorded on a Raman Fourier Transform spectrometer IFS 100 (Bruker, Berlin, Germany) preparing samples on an aluminium foil and operating at $633 \mathrm{~nm}$ wavelength with a $8 \mathrm{~mW}$ laser power.

DSC analyses ( 25 to $300{ }^{\circ} \mathrm{C}$ temperature range, $20 \mathrm{~mL} \mathrm{~min}^{-1}$ nitrogen flow rate, $0.5^{\circ} \mathrm{C} \mathrm{min}^{-1}$ heating rate) were performed using a DSC200 PC (NETZSCH-Gerätebau $\mathrm{GmbH}$, Selb, Germany) placing samples in aluminium pans hermetically sealed with aluminium lids. 
Four points method in the presence of argon pressure at room temperature was used to measure the electric conductivity of powder samples pressed in an insulating ceramic under a constant pressure of $100 \mathrm{MPa}$.

The swelling degree of hydrogels was investigated in water in the presence and absence of an external electric voltage as follows: specimens of $\sim 1.0 \mathrm{~cm}^{2}$ were cut from each sample and placed in a 5-mL sintered glass filter (porosity G3), weighted, and left to swell by immersing the filter in a beaker containing the swelling medium at $37^{\circ} \mathrm{C}$. At suitable time intervals, excess water was removed and samples weighed, after being blotted with a tissue to remove surface moisture.

The water content percentage, WR, was expressed by the following Equation (5):

$$
W R=\frac{W_{s}-W_{d}}{W_{d}} \times 100
$$

where $W_{s}$ and $W_{d}$ are the weights of swollen and dried hydrogels, respectively.

The mean diameters of hydrogels pore $(\xi)$ were determined by applying the empirical model proposed in the literature [47] according to the Equations (S20)-(S24) in Supplementary Materials).

\subsection{Batch Kinetics and Equilibrium Adsorption Studies}

The conditions used for dyes adsorption studies were as follows:

(i) isothermal studies: $4.0 \mathrm{mg} \mathrm{mL}^{-1} \mathrm{HG}_{\mathrm{NT}}, 0.05-0.4 \mathrm{mg} \mathrm{mL}^{-1}$ dye solution, contact time $1440 \mathrm{~min}$, temperature $20^{\circ} \mathrm{C}$

(ii) kinetics studies: $4.0 \mathrm{mg} \mathrm{mL}^{-1} \mathrm{HG}_{\mathrm{NT}}, 0.1 \mathrm{mg} \mathrm{mL}^{-1}$ dye solution, contact time 15-1440 min, temperature $20^{\circ} \mathrm{C}$

(iii) thermodynamics studies: $4.0 \mathrm{mg} \mathrm{mL}^{-1} \mathrm{HG}_{\mathrm{NT}}, 0.1 \mathrm{mg} \mathrm{mL}^{-1}$ dye solution, contact time $1440 \mathrm{~min}$, temperature range $4-50{ }^{\circ} \mathrm{C}$

After the reaction time, dyes concentration was determined by UV-Vis analyses on an Evolution 201 spectrophotometer (ThermoFisher Scientific, Hillsboro, OR, USA) operating with $1.0 \mathrm{~cm}$ quartz cells, by using the calibration curves of the dye $\left(0.001-0.01 \mathrm{mg} \mathrm{mL}^{-1}\right)$.

The experimental amount of adsorbed dye $\left(q_{\text {exp }}, \mathrm{mg} \mathrm{g}^{-1}\right)$ was expressed as follows (Equation (6)):

$$
q_{\text {exp }}=\frac{C_{0}-C_{f}}{m} \times V
$$

where $C_{0}$ and $C_{f}$ are the initial and final dyes concentration, respectively, $m$ is the amount of hydrogels, and $V$ is the volume of dye solution.

The adsorption capacity at time $\mathrm{t}\left(q_{t}\right)$ and at equilibrium $\left(q_{e}\right)$ were expressed using the Equations (S25) and (S26) in Supplementary Materials.

\subsection{Hydrogel Regeneration}

The regeneration of hydrogel matrices was performed by immersing aliquots ( 20 $\mathrm{mg}$ ) of dye loaded hydrogels (as reported in point (i) in Section3.3) in $100 \mathrm{~mL}$ fresh water solutions at different $\mathrm{pH}$ conditions, and (ii) as follows: phosphate buffer $0.01 \mathrm{M}, \mathrm{pH}$ 7.0; citrate buffer $0.01 \mathrm{M}, \mathrm{pH}$ 3.0; carbonate buffer $\mathrm{pH}$ 9.2. After $2 \mathrm{~h}$ hydrogel matrices were transferred to fresh desorption media and the desorption step was repeated till $24 \mathrm{~h}$.

Similarly, in separate experiments, the same amount of loaded hydrogels was placed in $100 \mathrm{~mL}$ water solution in the presence of a $12 \mathrm{~V}$ external electric voltage for $2 \mathrm{~h}$.

After determination of the released dye in solution by UV-Vis analysis on an Evolution 201 spectrophotometer (ThermoFisher Scientific, Hillsboro, OR, USA), the dye removal (\%) was calculated according to the following Equation (7):

$$
\text { Recovery }(\%)=\frac{D_{t}}{C_{0}-C_{f}} \times 100
$$


where $D_{t}$ is the concentration of dyes in the desorption media, $C_{0}$ and $C_{\mathrm{f}}$ the initial and final dyes concentration in the previously performed adsorption process, respectively.

\subsection{Statistical Analyses}

All measurements were done in triplicate and data expressed as means \pm SD. Thermodynamics, isothermal and kinetics parameters were calculated by OriginPro 2019 Software (OriginLab Corporation, Northampton, MA, USA).

\section{Conclusions}

Within the present study, experimental evidence that the high adsorption ability of MWCNT and the water affinity of acrylate polymer networks can be effectively combined for the fabrication of hybrid hydrogels suitable for wastewater treatment. More interestingly, the electro-responsivity of MWCNT allowed the modification of sorption capacity and rate upon the application of an external voltage, with the negative polarization of hybrid hydrogels resulting in enhanced or reduced sorption capacity for cationic and anionic (or neutral) molecules, respectively. For MB molecules, the application of the external voltage was found to enhance the $q_{\text {exp }}$ from $19.72 \mathrm{mg} \mathrm{g}^{-1}(0 \mathrm{~V})$ to $33.45 \mathrm{mg} \mathrm{g}^{-1}(12 \mathrm{~V})$, while a reduction from $28.93 \mathrm{mg} \mathrm{g}^{-1}(0 \mathrm{~V})$ to $13.06 \mathrm{mg} \mathrm{g}^{-1}(12 \mathrm{~V})$ and from $36.75 \mathrm{mg} \mathrm{g}^{-1}(0 \mathrm{~V})$ to $15.85 \mathrm{mg} \mathrm{g}^{-1}(12 \mathrm{~V})$ was recorded for RD and BR, respectively.

Thermodynamic, isothermal, and kinetics studies showed that (i) the adsorption processes were possible, spontaneous, and exothermic in all cases, (ii) physical sorbent to sorbate interactions with a predominant surface mechanism are involved; (iii) although predominant sorption processes are involved, the electronic behavior of both hydrogel surface and dye molecules plays a crucial role in determining the sorbent/sorbate interactions.

Regeneration studies showed that the dyes to hydrogel interactions are mainly disrupted in acidic (MB and $\mathrm{RD}$ ) or alkaline conditions (BR), with the sorption capacity being unchanged after 5 repeated cycles. Furthermore, the reduced affinity of the hybrid hydrogels for RD and BR under $12 \mathrm{~V}$ conditions was used as an alternative and effective regeneration method.

Although further experiments are needed to improve the sorbent capacity and investigate the performance in real wastewater sample, overall, our results have shown the potential of the CNT hybrid hydrogel system as a support for wastewater remediation in industrial practice.

Supplementary Materials: The following are available online, Figure S1: FT-IR of HGNT samples before (black line) and after (red line) the five sorption cycles, Figure S2: Surface appearance of $\mathrm{HG}_{\mathrm{NT}}$ (a) before and (b) after the five sorption cycles, Figure S3: SEM image of HGNT sample after the five sorption cycles, Figure S4: Raman patterns of $\mathrm{HG}_{\mathrm{NT}}$ sample after the five sorption cycles Equations (S1)-(S12): Isothermal studies, Equations (S13)-(S19): Kinetics studies, Equations (S20)-(S24): Mean diameter of hydrogels pore, Equations (S25)-(S26): Batch kinetics and equilibrium adsorption studies.

Author Contributions: Conceptualization, G.C. and F.P.N.; methodology, G.C. and F.P.N.; software, G.C. and F.P.N.; validation, G.C., F.I. and F.P.N.; formal analysis, F.I.; G.D.F. and S.H.; investigation, M.C. and L.F.M.; resources, F.P.N.; data curation, G.D.F. and S.H.; writing—original draft preparation, G.C.; writing—review and editing, F.P.N., G.D.F. and S.H.; visualization, M.C.; supervision, F.P.N. All authors have read and agreed to the published version of the manuscript.

Funding: This work was supported by MIUR Excellence Department Project funds (L.232/2016), awarded to the Department of Pharmacy, Health, and Nutritional Sciences, University of Calabria, Italy.

Institutional Review Board Statement: Not applicable.

Informed Consent Statement: Not applicable.

Data Availability Statement: Not applicable. 
Acknowledgments: In this section, you can acknowledge any support given which is not covered by the author contribution or funding sections. This may include administrative and technical support, or donations in kind (e.g., materials used for experiments).

Conflicts of Interest: The authors declare no conflict of interest.

\section{References}

1. Goncalves, J.O.; da Silva, K.A.; Rios, E.C.; Crispim, M.M.; Dotto, G.L.; Pinto, L.A.D. Chitosan Hydrogel Scaffold Modified with Carbon Nanotubes and Its Application for Food Dyes Removal in Single and Binary Aqueous Systems. Int. J. Biol. Macromol. 2020, 142, 85-93. [CrossRef]

2. Yao, Y.J.; Xu, F.F.; Chen, M.; Xu, Z.X.; Zhu, W. Adsorption Behavior of Methylene Blue on Carbon Nanotubes. Bioresour. Technol. 2010, 101, 3040-3046. [CrossRef] [PubMed]

3. Singh, A.; Goswami, A.; Nain, S. Enhanced Antibacterial Activity and Photo-Remediation of Toxic Dyes Using Ag/Swcnt/Ppy Based Nanocomposite with Core-Shell Structure. Appl. Nanosci. 2020, 10, 2255-2568. [CrossRef]

4. Wang, R.; Zhang, X.; Zhu, J.L.; Bai, J.H.; Gao, L.L.; Liu, S.F.; Jiao, T.F. Facile Preparation of Self-Assembled Chitosan-Based Composite Hydrogels with Enhanced Adsorption Performances. Colloids Surf. A-Physicochem. Eng. Asp. 2020, 598, 124860. [CrossRef]

5. Gita, S.; Shukla, S.P.; Deshmukhe, G.; Choudhury, T.G.; Saharan, N.; Singh, A.K. Toxicity Evaluation of Six Textile Dyes on Growth, Metabolism and Elemental Composition $(\mathrm{C}, \mathrm{H}, \mathrm{N}, \mathrm{S})$ of Microalgae Spirulina Platensis: The Environmental Consequences. Bull. Environ. Contam. Toxicol. 2021, 106, 302-309. [CrossRef]

6. Verma, Y. Acute Toxicity Assessment of Textile Dyes and Textile and Dye Industrial Effluents Using Daphnia Magna Bioassay. Toxicol. Ind. Health 2008, 24, 491-500. [CrossRef] [PubMed]

7. Slama, B.H.; Bouket, A.C.; Pourhassan, Z.; Alenezi, F.N.; Silini, A.; Cherif-Silini, H.; Oszako, T.; Luptakova, L.; Golinska, P.; Belbahri, L. Diversity of Synthetic Dyes from Textile Industries, Discharge Impacts and Treatment Methods. Appl. Sci. 2021, 11, 6255. [CrossRef]

8. Yu, G.J.; Zhao, X.H.; Yang, H.; Chen, X.H.; Yang, Q.; Yu, L.Y.; Jiang, J.H.; Chen, X.Q. Aqueous Adsorption and Removal of Organic Contaminants by Carbon Nanotubes. Sci. Total Environ. 2014, 482, 241-251. [CrossRef]

9. Zhu, M.; Miao, J.; Guan, D.Q.; Zhong, Y.J.; Ran, R.; Wang, S.B.; Zhou, W.; Shao, Z.P. Efficient Wastewater Remediation Enabled by Self-Assembled Perovskite Oxide Heterostructures with Multiple Reaction Pathways. ACS Sustain. Chem. Eng. 2020, 8, 6033-6042. [CrossRef]

10. Aditya, D.; Rohan, P.; Suresh, G. Nano-Adsorbents for Wastewater Treatment: A Review. Res. J. Chem. Environ. 2011, 15, 1033-1040.

11. Akter, M.; Bhattacharjee, M.; Dhar, A.K.; Rahman, F.B.; Haque, S.; Rashid, T.U.; Kabir, S.M.F. Cellulose-Based Hydrogels for Wastewater Treatment: A Concise Review. Gels 2021, 7, 30. [CrossRef]

12. Liu, J.; Su, D.H.; Yao, J.R.; Huang, Y.F.; Shao, Z.Z.; Chen, X. Soy Protein-Based Polyethylenimine Hydrogel and Its High Selectivity for Copper Ion Removal in Wastewater Treatment. J. Mater. Chem. A 2017, 5, 4163-4171. [CrossRef]

13. Tanan, W.; Panichpakdee, J.; Saengsuwan, S. Novel Biodegradable Hydrogel Based on Natural Polymers: Synthesis, Characterization, Swelling/Reswelling and Biodegradability. Eur. Polym. J. 2019, 112, 678-687. [CrossRef]

14. Tran, V.V.; Park, D.; Lee, Y.C. Hydrogel Applications for Adsorption of Contaminants in Water and Wastewater Treatment. Environ. Sci. Pollut. Res. 2018, 25, 24569-24599. [CrossRef] [PubMed]

15. Ren, J.; Wang, X.M.; Zhao, L.L.; Li, M.; Yang, W. Effective Removal of Dyes from Aqueous Solutions by a Gelatin Hydrogel. J. Polym. Environ. 2021, 29, 3497-3508. [CrossRef]

16. Shafiee, M.R.N.; Parhizkar, J.; Radfar, S. Removal of Rhodamine B by G-C3n4/Co3o4/Mwcnt Composite Stabilized in Hydrogel Via the Synergy of Adsorption and Photocatalysis under Visible Light. J. Mater. Sci.-Mater. Electron. 2019, 30, 12475-12486. [CrossRef]

17. Mansoori, S.; Davarnejad, R.; Matsuura, T.; Ismail, A.F. Membranes Based on Non-Synthetic (Natural) Polymers for Wastewater Treatment. Polym. Test. 2020, 84, 106381. [CrossRef]

18. Hu, S.X.; Liang, R.; Li, J.; Liu, Z.P.; Sun, G.X. Mechanically Strong Hydrogels Achieved by Designing Homogeneous Network Structure. Mater. Des. 2019, 163, 107547. [CrossRef]

19. Sinha, V.; Chakma, S. Advances in the Preparation of Hydrogel for Wastewater Treatment: A Concise Review. J. Environ. Chem. Eng. 2019, 7, 103295. [CrossRef]

20. Jing, H.G.; Wang, L.; Yu, H.J.; Amer, W.A.; Zhang, L. Recent Progress on Study of Hybrid Hydrogels for Water Treatment. Colloids Surf. A-Physicochem. Eng. Asp. 2013, 416, 86-94. [CrossRef]

21. Dehne, H.; Hecht, F.M.; Bausch, A.R. The Mechanical Properties of Polymer-Colloid Hybrid Hydrogels. Soft Matter 2017, 13, 4786-4790. [CrossRef] [PubMed]

22. Cui, W.; Ji, J.; Cai, Y.F.; Li, H.; Ran, R. Robust, Anti-Fatigue, and Self-Healing Graphene Oxide/Hydrophobically Associated Composite Hydrogels and Their Use as Recyclable Adsorbents for Dye Wastewater Treatment. J. Mater. Chem. A 2015, 3, 17445-17458. [CrossRef] 
23. Subhan, H.; Alam, S.; Shah, L.A.; Ali, M.W.; Farooq, M. Sodium Alginate Grafted Poly(N-Vinyl Formamide-Co-Acrylic Acid)Bentonite Clay Hybrid Hydrogel for Sorptive Removal of Methylene Green from Wastewater. Colloids Surf. A-Physicochem. Eng. Asp. 2021, 611, 125853. [CrossRef]

24. Bahgat, M.; Farghali, A.A.; el Rouby, W.M.A.; Khedr, M.H. Synthesis and Modification of Multi-Walled Carbon Nano-Tubes (Mwcnts) for Water Treatment Applications. J. Anal. Appl. Pyrolysis 2011, 92, 307-313. [CrossRef]

25. Hosseinzadeh, H. Synthesis of Carrageenan/Multi-Walled Carbon Nanotube Hybrid Hydrogel Nanocomposite for Adsorption of Crystal Violet from Aqueous Solution. Pol. J. Chem. Technol. 2015, 17, 70-76. [CrossRef]

26. Navrotskaya, G.A.; Aleksandrova, D.D.; Krivoshapkina, E.F.; Sillanpaa, M.; Krivoshapkin, P.V. Hybrid Materials Based on Carbon Nanotubes and Nanofibers for Environmental Applications. Front. Chem. 2020, 8, 546. [CrossRef] [PubMed]

27. Makhado, E.; Hato, M.J. Preparation and Characterization of Sodium Alginate-Based Oxidized Multi-Walled Carbon Nanotubes Hydrogel Nanocomposite and Its Adsorption Behavior for Methylene Blue Dye. Front. Chem. 2021, 9, 576913. [CrossRef]

28. Vo, S.T.; Vo, T.T.B.C.; Suk, J.W.; Kim, K. Recycling Performance of Graphene Oxide-Chitosan Hybrid Hydrogels for Removal of Cationic and Anionic Dyes. Nano Converg. 2020, 7, 4. [CrossRef]

29. Yan, L.; Chang, P.R.; Zheng, P.W.; Ma, X.F. Characterization of Magnetic Guar Gum-Grafted Carbon Nanotubes and the Adsorption of the Dyes. Carbohydr. Polym. 2012, 87, 1919-1924. [CrossRef]

30. Curcio, M.; Spizzirri, U.G.; Cirillo, G.; Vittorio, O.; Picci, N.; Nicoletta, F.P.; Iemma, F.; Hampel, S. On Demand Delivery of Ionic Drugs from Electro-Responsive Cnt Hybrid Films. RSC Adv. 2015, 5, 44902-44911. [CrossRef]

31. Mhatre, S.; Simon, S.; Sjoblom, J. Experimental Evidence of Enhanced Adsorption Dynamics at Liquid-Liquid Interfaces under an Electric Field. Anal. Chem. 2020, 92, 12860-12870. [CrossRef]

32. Benavidez, E.T.; Torrente, D.; Marucho, M.; Garcia, C.D. Adsorption of Soft and Hard Proteins onto Otces under the Influence of an External Electric Field. Langmuir 2015, 31, 2455-2462. [CrossRef] [PubMed]

33. Stasaid, M.; Boutemak, K.; Ibtissem, L.; Flahaut, E.; Hadj-Ziane-Zafour, A. Synthesis of Carboxymethyl Xanthan/Double-Walled Carbon Nanotube Hybrid Hydrogel Nanocomposite for Transdermal Release of Drug. Soft Mater. 2021, 1-15. [CrossRef]

34. Cirillo, G.; Hampel, S.; Spizzirri, U.G.; Parisi, O.I.; Picci, N.; Iemma, F. Carbon Nanotubes Hybrid Hydrogels in Drug Delivery: A Perspective Review. Biomed Res. Int. 2014, 2014, 825017. [CrossRef]

35. Shakeri, A.; Nakhjiri, M.T.; Salehi, H.; Ghorbani, F.; Khankeshipour, N. Preparation of Polymer-Carbon Nanotubes Composite Hydrogel and Its Application as Forward Osmosis Draw Agent. J. Water Process. Eng. 2018, 24, 42-48. [CrossRef]

36. Cirillo, G.; Caruso, T.; Hampel, S.; Haase, D.; Puoci, F.; Ritschel, M.; Leonhardt, A.; Curcio, M.; Iemma, F.; Khavrus, V.M.; et al. Novel Carbon Nanotube Composites by Grafting Reaction with Water-Compatible Redox Initiator System. Colloid Polym. Sci. 2013, 291, 699-708. [CrossRef]

37. Ahmed, S.D.; Haider, A.J.; Mohammad, M.R. Comparesion of Functionalization of Multi-Walled Carbon Nanotubes Treated by Oil Olive and Nitric Acid and Their Characterization. Energy Procedia 2013, 36, 1111-1118. [CrossRef]

38. Tugulu, S.; Barbey, R.; Harms, M.; Fricke, M.; Volkmer, D.; Rossi, A.; Klok, H.A. Synthesis of Poly(Methacrylic Acid) Brushes Via Surface-Initiated Atom Transfer Radical Polymerization of Sodium Methacrylate and Their Use as Substrates for the Mineralization of Calcium Carbonate. Macromolecules 2007, 40, 168-177. [CrossRef]

39. Cirillo, G.; Curcio, M.; Spizzirri, U.G.; Vittorio, O.; Tucci, P.; Picci, N.; Iemma, F.; Hampel, S.; Nicoletta, F.P. Carbon Nanotubes Hybrid Hydrogels for Electrically Tunable Release of Curcumin. Eur. Polym. J. 2017, 90, 1-12. [CrossRef]

40. Rashid, R.; Shafiq, I.; Akhter, P.; Iqbal, M.J.; Hussain, M. A State-of-the-Art Review on Wastewater Treatment Techniques: The Effectiveness of Adsorption Method. Environ. Sci. Pollut. Res. 2021, 28, 9050-9066. [CrossRef]

41. Wawrzkiewicz, M.; Polska-Adach, E.; Hubicki, Z. Application of Titania Based Adsorbent for Removal of Acid, Reactive and Direct Dyes from Textile Effluents. Adsorpt. J. Int. Adsorpt. Soc. 2019, 25, 621-630. [CrossRef]

42. Anil, I.; Gunday, S.T.; Bozkurt, A.; Alagha, O. Design of Crosslinked Hydrogels Comprising Poly(Vinylphosphonic Acid) and Bis[2-(Methacryloyloxy)Ethyl] Phosphate as an Efficient Adsorbent for Wastewater Dye Removal. Nanomaterials 2020, 10, 131. [CrossRef]

43. Yang, Y.C.; Xu, W.X.; Nan, Y.; Wang, Y.G.; Hu, Y.X.; Gao, C.J.; Chen, X.H. Fabrication and Characterization of a High Performance Polyimide Ultrafiltration Membrane for Dye Removal. J. Colloid Interface Sci. 2020, 562, 589-597. [CrossRef]

44. Khatri, J.; Nidheesh, P.V.; Singh, S.A.; Kumar, M.S. Advanced Oxidation Processes Based on Zero-Valent Aluminium for Treating Textile Wastewater. Chem. Eng. J. 2018, 348, 67-73. [CrossRef]

45. Mallakpour, S.; Behranvand, V.; Mallakpour, F. Adsorptive Performance of Alginate/Carbon Nanotube-Carbon Dot-Magnesium Fluorohydroxyapatite Hydrogel for Methylene Blue-Contaminated Water. J. Environ. Chem. Eng. 2021, 9, 105170. [CrossRef]

46. Mallakpour, S.; Tabesh, F. Green and Plant-Based Adsorbent from Tragacanth Gum and Carboxyl-Functionalized Carbon Nanotube Hydrogel Bionanocomposite for the Super Removal of Methylene Blue Dye. Int. J. Biol. Macromol. 2021, 166, 722-729. [CrossRef]

47. Kulkarni, R.A.; Soppimath, K.S.; Aminabhavi, T.M.; Dave, A.M.; Mehta, M.H. Glutaraldehyde Crosslinked Sodium Alginate Beads Containing Liquid Pesticide for Soil Application. J. Control. Release 2000, 63, 97-105. [CrossRef]

48. Tsai, C.H.; Lin, J.Y.; Maryani, F.; Huang, C.C.; Imae, T. Drug-Loading Capacity and Nuclear Targeting of Multiwalled Carbon Nanotubes Grafted with Anionic Amphiphilic Copolymers. Int. J. Nanomed. 2013, 8, 4427-4440. [CrossRef]

49. Hilder, A.T.; Hill, J.M. Modeling the Loading and Unloading of Drugs into Nanotubes. Small 2009, 5, 300-308. [CrossRef] 
50. Peighambardoust, J.S.; Aghamohammadi-Bavil, O.; Foroutan, R.; Arsalani, N. Removal of Malachite Green Using Carboxymethyl Cellulose-G- Polyacrylamide/Montmorillonite Nanocomposite Hydrogel. Int. J. Biol. Macromol. 2020, 159, 1122-1131. [CrossRef]

51. Salam, A.M.; El-Shishtawy, R.M.; Obaid, A.Y. Synthesis of Magnetic Multi-Walled Carbon Nanotubes/Magnetite/Chitin Magnetic Nanocomposite for the Removal of Rose Bengal from Real and Model Solution. J. Ind. Eng. Chem. 2014, 20, 3559-3567. [CrossRef]

52. Fan, C.J.; Shi, Z.X.; Lian, M.; Li, H.; Yin, J. Mechanically Strong Graphene Oxide/Sodium Alginate/Polyacrylamide Nanocomposite Hydrogel with Improved Dye Adsorption Capacity. J. Mater. Chem. A 2013, 1, 7433-7443. [CrossRef]

53. Rajabi, M.; Mahanpoor, K.; Moradi, O. Removal of Dye Molecules from Aqueous Solution by Carbon Nanotubes and Carbon Nanotube Functional Groups: Critical Review. RSC Adv. 2017, 7, 47083-47090. [CrossRef]

54. Cheng, L.Z.; Li, Y.X.; Liu, Z. Novel Adsorption Materials Based on Graphene Oxide/Beta Zeolite Composite Materials and Their Adsorption Performance for Rhodamine B. J. Alloy. Compd. 2017, 708, 255-263. [CrossRef]

55. Tao, J.X.; Wang, S.; Li, Z.W. Ultrasound-Assisted Bottom-up Synthesis of Ni-Graphene Hybrid Composites and Their Excellent Rhodamine B Removal Properties. J. Environ. Manag. 2020, 255, 109834. [CrossRef]

56. Ayawei, N.; Ebelegi, A.N.; Wankasi, D. Modelling and Interpretation of Adsorption Isotherms. J. Chem. 2017, $2017,3039817$. [CrossRef]

57. Kamga, F.T. Modeling Adsorption Mechanism of Paraquat onto Ayous (Triplochiton Scleroxylon) Wood Sawdust. Appl. Water Sci. 2019, 9, 1. [CrossRef]

58. Sharma, K.A.; Priya; Kaith, B.S.; Bajaj, S.; Bhatia, J.K.; Panchal, S.; Sharm, N.; Tanwar, V. Efficient Capture of Eosin Yellow and Crystal Violet with High Performance Xanthan-Acacia Hybrid Super-Adsorbent Optimized Using Response Surface Methodology. Colloids Surf. B-Biointerfaces 2019, 175, 314-323. [CrossRef]

59. Pashaei-Fakhri, S.; Peighambardoust, S.J.; Foroutan, R.; Arsalani, N.; Ramavandi, B. Crystal Violet Dye Sorption over Acrylamide/Graphene Oxide Bonded Sodium Alginate Nanocomposite Hydrogel. Chemosphere 2021, 270, 129419. [CrossRef] [PubMed]

60. Belhachemi, M.; Addoun, F. Comparative Adsorption Isotherms and Modeling of Methylene Blue onto Activated Carbons. Appl. Water Sci. 2011, 1, 111-117. [CrossRef]

61. Zhou, Y.; Jin, X.Y.; Lin, H.F.; Chen, Z.L. Synthesis, Characterization and Potential Application of Organobentonite in Removing 2,4-Dcp from Industrial Wastewater. Chem. Eng. J. 2011, 166, 176-183. [CrossRef]

62. Qin, G.P.; Yang, Y.X.; Zhang, X.T.; Niu, J.H.; Yang, H.; Tian, S.F.; Zhu, J.H.; Lu, M.H. Highly Efficient, Rapid, and Simultaneous Removal of Cationic Dyes from Aqueous Solution Using Monodispersed Mesoporous Silica Nanoparticles as the Adsorbent. Nanomaterials 2018, 8, 4. [CrossRef] [PubMed]

63. Yu, C.Z.; Hu, C.S.; Dichiara, A.B.; Jiang, W.H.; Gu, J. Cellulose Nanofibril/Carbon Nanomaterial Hybrid Aerogels for Adsorption Removal of Cationic and Anionic Organic Dyes. Nanomaterials 2020, 10, 169. [CrossRef]

64. Yamashita, H.; Tanaka, A.; Nishimura, M.; Koyano, K.; Tatsumi, T.; Anpo, M. Photochemical Properties of Rhodamine-B Dye Molecules Included within Mesoporous Molecular Sieves. Mesoporous Mol. Sieves 1998, 177, 551-558.

65. Daraio, M.E.; San Roman, E. Aggregation and Photophysics of Rose Bengal in Alumina-Coated Colloidal Suspensions. Helv. Chim. Acta 2001, 84, 2601-2614. [CrossRef]

66. Hanbali, M.; Holail, H.; Hammud, H. Remediation of Lead by Pretreated Red Algae: Adsorption Isotherm, Kinetic, Column Modeling and Simulation Studies. Green Chem. Lett. Rev. 2014, 7, 342-358. [CrossRef]

67. Gurses, A.; Dogar, C.; Yalcin, M.; Acikyildiz, M.; Bayrak, R.; Karaca, S. The Adsorption Kinetics of the Cationic Dye, Methylene Blue, onto Clay. J. Hazard. Mater. 2006, 131, 217-228. [CrossRef]

68. Al-Ghouti, M.A.; Khraisheh, M.A.M.; Ahmad, M.N.M.; Allen, S. Adsorption Behavior of Methylene Blue onto Jordanian Diatomite: A Kinetic Study. J. Hazard. Mater. 2009, 165, 589-598. [CrossRef]

69. Malash, G.F.; El-Khaiary, M.I. Methylene Blue Adsorption by the Waste of Abu-Tartour Phosphate Rock. J. Colloid Interface Sci. 2010, 348, 537-545. [CrossRef]

70. Yu, Y.; Murthy, B.N.; Shapter, J.G.; Constantopoulos, K.T.; Voelcker, N.H.; Ellis, A.V. Benzene Carboxylic Acid Derivatized Graphene Oxide Nanosheets on Natural Zeolites as Effective Adsorbents for Cationic Dye Removal. J. Hazard. Mater. 2013, 260, 330-338. [CrossRef] [PubMed]

71. Vargas, M.A.M.; Cazetta, A.L.; Kunita, M.H.; Silva, T.L.; Almeida, V.C. Adsorption of Methylene Blue on Activated Carbon Produced from Flamboyant Pods (Delonix Regia): Study of Adsorption Isotherms and Kinetic Models. Chem. Eng. J. 2011, 168, 722-730. [CrossRef]

72. Ahmad, M.A.; Puad, N.A.A.; Bello, O.S. Kinetic, Equilibrium and Thermodynamic Studies of Synthetic Dye Removal Using Pomegranate Peel Activated Carbon Prepared by Microwave-Induced Koh Activation. Water Resour. Ind. 2014, 6, 18-35. [CrossRef] 